\title{
EVOLUÇÃO DO RELEVO DA REGIÃO DO PLANALTO DE POÇOS DE CALDAS (SP/MG) BASEADO EM DADOS DE TERMOCRONOLOGIA DE BAIXA TEMPERATURA E MODELAGEM TERMOCINEMÁTICA 3D
}

\section{RELIEF EVOLUTION OF POÇOS DE CALDAS (SP/MG) REGION BASED IN THERMOCHRONOLOGY DATA AND 3D THERMOKINEMATIC MODELING}

Carolina Doranti-Tiritan
Instituto de Geociências e Ciências Exatas, Universidade Estadual Paulista.
Avenida 24 A, 1515, Bela Vista, Rio Claro/SP. Cep 13.506-900. Brasil.
E-mail: cadoranti@gmail.com

Peter Christian Hackspacher

Instituto de Geociências e Ciências Exatas, Universidade Estadual Paulista. Avenida 24 A, 1515, Bela Vista, Rio Claro/SP. Cep 13.506-900. Brasil.

E-mail: phack@rc.unesp.br

Marli Carina Siqueira Ribeiro Instituto de Geociências e Ciências Exatas, Universidade Estadual Paulista. Avenida 24 A, 1515, Bela Vista, Rio Claro/SP. Cep 13.506-900. Brasil. E-mail: marlicarina@gmail.com

Ulrich. A. Glasmacher

Institute of Earth Sciences, Heidelberg University. Im Neuenheimer Feld, 234, Heidelberg. Cep 69120. Alemanha. E-Mail: ulrich.a.glasmacher@geow.uni-heidelberg.de

Daniel Henrique de Souza

Instituto de Geociências e Ciências Exatas, Universidade Estadual Paulista. Avenida 24 A, 1515, Bela Vista, Rio Claro/SP - Cep: 13.506-900. Brasil.

E-mail: danieudani@yahoo.com.br

Informações sobre o Artigo

Data de Recebimento:

$15 / 01 / 2014$

Data de Aprovação:

$16 / 05 / 2014$

\section{Resumo:}

A região do Planalto de Poços de Caldas no sudeste do Brasil é caracterizada principalmente pelos seus planaltos elevados sustentados por rochas cristalinas do Pré-Cambriano e Cambro-Ordoviciano cortados por intrusivas alcalinas do final do período Cretáceo. Nessa região a maior particularidade está na intrusão alcalina de Poços de Caldas (MAPC), que deu origem ao planalto de mesmo nome, e que vem sendo estudada há muito tempo por vários campos das ciências 


\section{Palavras-chave:}

Evolução da Paisagem;

Termocronologia; Poços de

Caldas/Minas Gerais

\section{Keywords:}

Landscape evolution; thermochronology; Poços de Caldas/Minas Gerais especialmente geológicos e geomorfológicos. A idade da intrusão é de 80 a $50 \mathrm{Ma}$ o que permite definir um limite temporal pra os processos formadores da drenagem e das formas de relevo na região. Assim, o objetivo principal foi quantificar os processos formadores da paisagem a partir de métodos quantitativos com a termocronologia de baixa temperatura, análise Morfométrica da rede de drenagem e a modelagem termocinemática 3D, a fim de obter dados sobre as taxas de soerguimento e erosão e sua correlação com os diferentes gradientes geotérmicos da região. Os resultados mostram que apesar da intrusão alcalina ter aquecido consideravelmente a região ela, não afetou profundamente o grau geotérmico da Zona Cristalina do Norte (ZCN), o que explica as idades mais antigas. Enquanto isso a região do MAPC as idades são mais jovens e o grau geotérmico mais elevado, assim como sua topografia. Assim conclui-se que nessa região as áreas com menores altitudes e mais frias irão preservar idades mais antigas do que as regiões mais elevadas com alto grau geotérmico.

\begin{abstract}
:
The Poços de Caldas Plateau region, in southeastern Brazil, is characterized mainly by high plateaus sustained by crystalline rocks of the Precambrian and Cambro-Ordovician cut by alkaline intrusive of the late Cretaceous period. In this region the great particularity is in the alkaline intrusion in Poços de Caldas (MAPC), which rise to the plateau of the same name, and which has been studied for a long time for various fields of Geosciences especially geological and geomorphological. The age of the intrusion is $\sim 83 \mathrm{Ma}$ which allows you to set a time limit for the process responsible for the development of the drainage system and landforms of the region. The main objective of this work was to quantify those processes from quantitative methods with low-temperature thermochronology and thermokinetic 3D modelling, in order to obtain exumation and erosion rates and their correlation with different geothermal gradients. The results show that despite the alkaline intrusion have heated considerably in the region, not profoundly affected the geothermalg gradient of the North Crystalline Zone (ZCN), which explains the older ages. Meanwhile the MAPC region has the youngest ages, and also the highest geothermal gradient and consequently the highest elevation. So it appears that in this region the areas with lower altitudes and cooler will preserve ages older than the higher regions with high grade geothermal.
\end{abstract}

\section{Introdução}

A evolução da paisagem na superfície terrestre é controlada pela interação entre a atuação de processos tectônicos e superficiais, sendo que entender o funcionamento desta dinâmica entre ambos tem sido fundamental para a criação de novos modelos dessa evolução em diversas regiões do planeta (REINERS \& SHUSTER, 2009). Para buscar respostas sobre como se dá essa evolução, e entender quais os processos atuam com mais intensidade na transformação do relevo, tem-se utilizado como uma das ferramentas de análise, a termocronologia de baixa temperatura em conjunto com análises superficiais e também outros métodos de datação.

As técnicas termocronológicas mais utilizadas para estudos de evolução da paisagem são a análise de traços de fissão (TFA) e a sistemática (U-Th-Sm)/
He em apatitas, pois essas datam a passagem da rocha pelas isotermas de 110 e $60^{\circ} \mathrm{C}$ respectivamente, ou seja, quando essas rochas estavam por volta de 1 a $3 \mathrm{~km}$ de profundidade. Conforme a topografia muda ocorre também mudanças na respectiva isoterma, ocorrendo também mudanças nas taxas de soerguimento e exumação. Essas alterações na isoterma diminuem exponencialmente conforme a profundidade (BRAUN, 2002a). Assim essas técnicas vão fornecer ferramentas que possibilitam obter conclusões a respeito dos eventos que atuaram na região sejam eles soerguimento tectônico, erosão ou exumação.

No Brasil a metodologia vem sendo utilizada com frequência principalmente na região sudeste (GALLAGHER et al. 1994; HACKSPACHER et al. 2004; TELLO SAENZ et al. 2005; COGNÉ et al. 2011) possibilitando um melhor entendimento dos eventos que foram responsáveis pela estruturação de diferentes 
setores da Plataforma Sulamericana. Assim é possível reconhecer e identificar pulsos de soerguimento e erosão associados a soerguimentos tectônicos, que ocorreram em zonas aquecidas da plataforma, a partir do Cretáceo (FRANCO-MAGALHÃES, 2010).

A escolha da região do Maciço Alcalino de Poços de Caldas foi motivada por suas diferentes peculiaridades geológicas e geomorfológicas, que foram destacadas por autores como King (1956) e Almeida (1964). A principal feição a se destacar é o relevo produzido pela grande intrusão alcalina que elevou a paisagem da região a mais de $1500 \mathrm{~m}$ de altitude, há 80 milhões de anos atrás. Essa região foi ainda afetada pela tectônica do final do período Cretáceo Superior responsável pela formação dos sistemas de rifts do sudeste do Brasil, o que alterou algumas das formas de relevo da região, bem como os padrões de drenagem.

Acredita-se também que nessa região ouve a atuação de ciclos erosivos que modelaram a paisagem formando extensas superfícies erosivas (KING, 1956) que posteriormente foram escalonadas devido movimentações tectônicas pós-intrusão (ALMEIDA 1964).

Assim esse trabalho buscou realizar a quantificação e identificação dos processos responsáveis pela evolução do relevo a partir do período Cretáceo Inferior, utilizando métodos como a análise de dados termocronológicos, como os traços de fissão em apatitas e da modelagem termocinemática 3D. Essa quantificação se faz importante para o entendimento da paisagem atual, pois permitem analisar diferentes hipóteses, de modo a estabelecer a idade, estilo e magnitude dos eventos tectônicos e denudacionais responsáveis pela caracterização do relevo nessa região.

\section{Contexto Geológico-Geomorfológico Regional}

No contexto geológico, a área de estudo está inserida no segmento central da Província Mantiqueira, correspondendo à região extremo-sul da Faixa Brasília (HEILBRON, et al., 2004) (Figura 1). Este setor insere-se em um sistema de nappes frontais, o Terreno Socorro-Guaxupé, que estão estruturalmente controlados por cavalgamentos com orientações de rumo ENE, respectivo ao Grupo Araxá (CAMPOS NETO \& CABY, 1999). Este sistema inclui rochas do embasamento de diferentes idades, incluindo gnaisses de alto grau do Complexo Amparo e ainda rochas do
Complexo Varginha-Guaxupé descritas por Cavalcanti et. al. (1979).

A partir do Neo-Jurássico a região esteve sujeita aos fenômenos relacionados à reativação tectônica do Mesozóico, denominada de Reativação Wealdeniana (ALMEIDA, 1967), que evoluíram sucessivamente para a ruptura continental do Gondwana e a abertura do Oceano Atlântico. O processo de rifteamento constituiu-se em um evento distencional precedido de magmatismo basáltico toleítico ocorrido na época em ambiente terrestre abrangendo áreas que hoje formam o assoalho das Bacias de Campos e Santos, os enxames de diques de direção NE-SW no embasamento costeiro e os basaltos da formação Serra Geral na Bacia do Paraná (MILANI, 2004). Com o peso do material de origem vulcânica e a consequente compactação do material sedimentar ocorre um continuo processo de subsidência na Bacia do Paraná, ocorrendo logo em seguida a deposição do Grupo Bauru (MILANI, 1997) no início do período Cretáceo (DIAS BRITO et al. 2001). Nessa mesma época ocorre a formação inicial da Serra da Mantiqueira em decorrência do soerguimento marginal de flancos de rift iniciado durante a abertura oceânica (TELLO SAENZ et al. 2003; HACKSPACHER et al. 2004).

Com o fim da fase de rifteamento na região Sudeste, em aproximadamente $98 \mathrm{Ma}$, inicia-se a fase de deriva continental, onde ocorre um processo de soerguimento epirogenetico generalizado no embasamento cristalino pré-Cambriano. Dois pulsos ascencionais do embasamento são reconhecidos por Zalán \& Oliveira (2005). O primeiro pulso, de natureza regional, teria sido acompanhado por intrusões/diques alcalinos com idades entre 82 and 52 Ma (ZALÁN, 2004) e teria como caracteristica a ausência de tectonismo de qualquer natureza.

A crosta continental teria então sofrido um soerguimento uniforme e os stocks alcalinos apresentndo um decréscimo nas idades entre Poços de Caldas e Cabo Frio sugerem que o alinhamento magmático tenha surgido em resposta à passagem da crosta continental espessa da Placa Sul Americana sobre o hot spot de Trindade (ZALÁN \& OLIVEIRA, 2005). Os autores colocam ainda que no final do periodo Cretáceo um mega planalto é gerado sendo invadido por intrusoes de natureza alcalina, sendo denominado de Serra do Mar Cretácea, posteriormente aplainada pela superfície Japi em torno de uma altitude média de $2000 \mathrm{~m}$. A grande elevação do megaplanalto teria dado origem ao segundo pulso, 


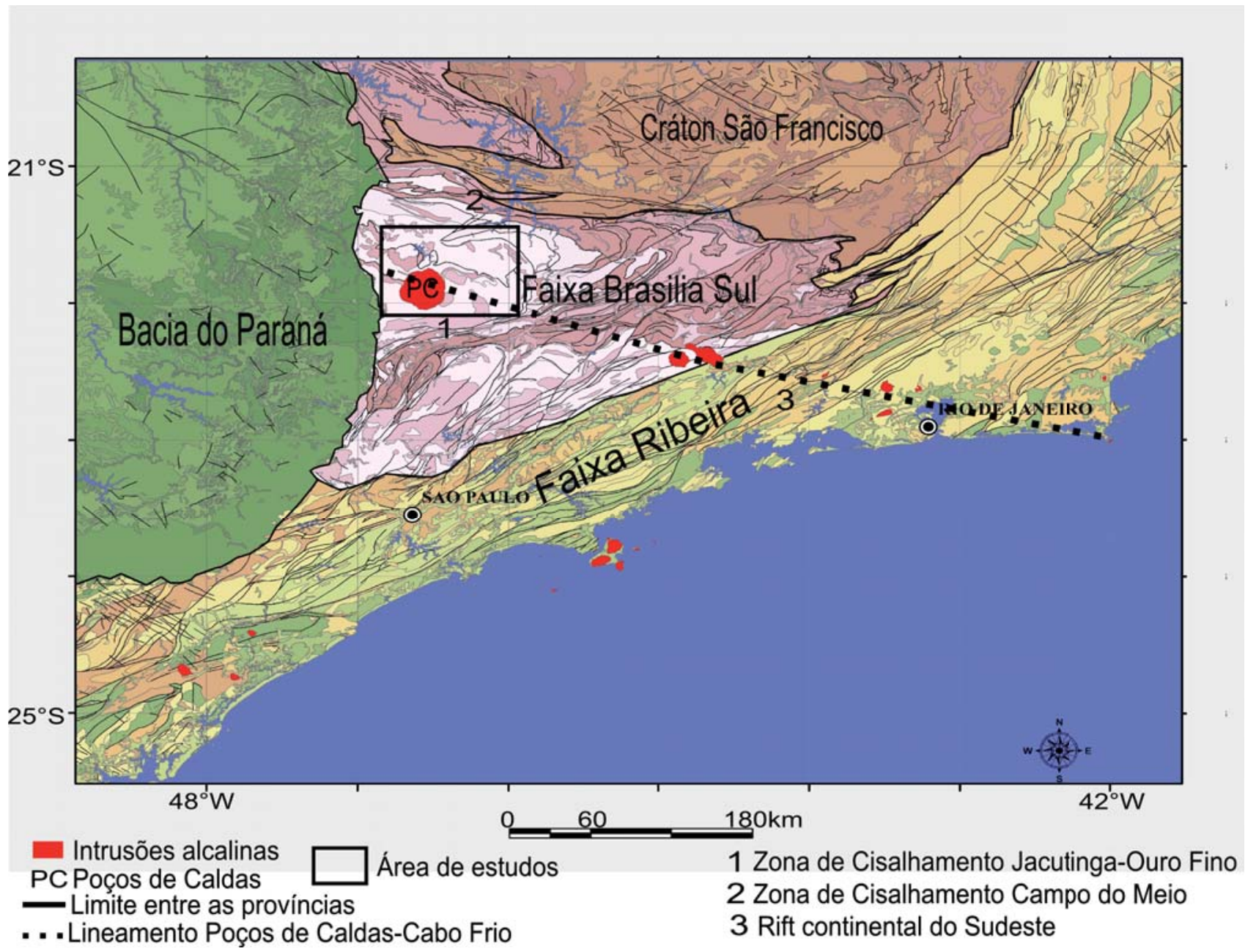

Figura 1 - Mapa Geológico Regional Simplificado. O mapa ilustra as províncias da Região Sudeste (Faixa Ribeira, Faixa Brasilia Sul, Cráton do São Francisco e Bacia do Paraná). Em vermelho as intrusões alcalinas, o alinhamento magmático Poços de Caldas-Cabo Frio. 1. Representa a zona de cisalhamento Jacutinga-Ouro Fino; 2. Zona de Cisalhamento Campo do Meio; 3. Rift continental do Sudeste.

que segundo os autores teria tido natureza de colapso.

A grande diferença altimétrica entre o flanco leste e a bacia de Santos teria levado ao inicio de colapsos e rachaduras locais no final do Paleoceno. É nesse período que ocorre um novo pulso ascensional levando à abertura do Sistema de Riftes Continentais do Sudeste. Dados de traço de fissão em apatitas data o evento como pós-60 Ma (TELLO SAENZ et al.. 2003), com clímax no Eoceno-Oligoceno (HACKSPACHER et al.. 2003).

\section{O alinhamento magmático Poços de Caldas-Cabo Frio}

O "Alinhamento de Rochas Alcalinas Poços de Caldas-Cabo Frio" (ALMEIDA et al.. 1996) é uma sequência de eventos vulcânicos localizados, representados por rochas alcalinas que formam stocks, plugs, possíveis chaminés, diques, derrames e piroclásticas (THOMAZ FILHO \& RODRIGUEZ 1999). Teria sido formado na segunda fase do magmatismo alcalino iniciado no Eocretáceo com fortes manifestações no Eoceno (ALMEIDA et al. 1991).

As idades dos stocks alcalinos de Poços de Caldas a São João/Cabo Frio decrescem gradualmente (THOMAZ FILHO et al. 2005) sugerindo a passagem de leste para oeste da crosta continental espessa da Placa Sul-Americana sobre um "hot spot" ou seja um foco de calor relativamente fixo (SADOWSKI \& DIAS NETTO, 1981). Entretanto, Zalán \& Oliveira (2005) colocam que tal anomalia térmica não seria intensa o suficiente 
para ser chamada de pluma mantélica e espalhada demais para ser caracterizada como um simples hot spot.

As primeiras datações no MAPC são em zircões provenientes de veios cortando o corpo alcalino utilizando o método chumbo-alfa (DUTRA, 1966). Esse autor obteve idades entre 109 e $87 \mathrm{Ma}$ (Cretáceo). Amaral et al.. (1967), utilizando o método K-Ar, obtiveram idades entre 80 e $62 \mathrm{Ma}$ (Cretáceo Superior). Guimarães \& Viana (1970 apud MOREIRA, et al. 2007) dataram uma amostra de Poços de Caldas utilizando o método K-Ar, e obtiveram a idade de $177 \pm 8,5 \mathrm{Ma}$, enquanto Bushee (1971) obteve, para as diversas fases magmáticas, as seguintes idades:

- lavas ankaratríticas: pelo menos $87 \mathrm{Ma}$;

- rochas do dique anelar: entre 81 e $80 \mathrm{Ma}$;

- derrame de fonólitos: entre 81 e $80 \mathrm{Ma}$;

- massa principal de tinguaítos e fonólitos: entre 78 e $72 \mathrm{Ma}$;

- intrusão de corpos sieníticos: entre 64 e $60 \mathrm{Ma}$; - diques de fonólitos: $53 \mathrm{Ma}$.

Amaral et al. (1967) determinaram a idade para os diques de fonólito como sendo $53 \mathrm{Ma}$, enquanto Kawashita et al., (1984) sugerem que os maiores valores devem ser os mais prováveis para a idade do vulcanismo. Entretanto, Ulbrich et al., (2002) analizando todas as idades disponíveis e descartando as análises menos confiáveis, sugere que a intrusão teve seu inicio por volta de $80 \mathrm{Ma}$, durando apenas $11 \mathrm{Ma}$. A figura 2 a seguir ilustra o mapa geológico da região com a localização das amostras coletadas.

\section{Geomorfologia da Região do MAPC}

Com relação a geomorfologia regional a área estudada insere-se na Província do Planalto Altântico (PONÇANO et al.. 1981) se restringindo as subdivisões denominadas Planalto Sul de Minas e Zona Cristalina do Norte (CAVALCANTI, et.al. 1979). Segundo Ponçano et. al. (1981) a área possui uma das feições mais marcantes do relevo, sendo encontrados níveis planálticos intercalados por serras. Almeida \& Carneiro (1998) identificaram planaltos e escarpas localizadas em regiões topograficamente altas, demonstrando evidências de uma erosão intensa, de forma que as principais superfícies de erosão pós-Paleozóicas da região SE do
Planalto Atlântico sejam observadas na área.

A superfície Sul-Americana (KING, 1956) ou Japi (ALMEIDA, 1964) é a principal superfície de erosão identificada na área. Apresenta grande extensão no SE do Brasil e nivela os topos e serras, atingindo altitudes de 1200 a $1300 \mathrm{~m}$, como é o caso das intrusões alcalinas cretáceas da Serra da Mantiqueira, do oeste do estado de Minas Gerais e sudeste do estado de Goiás (ALMEIDA, 1964).

De acordo com Magalhães \& Trindade (2004), a topografia nivelada entre $\sim 960$ a $1240 \mathrm{~m}$ corresponderia ao nível da Superfície Sul Americana, que representaria uma zona intermediária entre as bordas de blocos mais elevados, sujeitas a soerguimentos mais intensos ao longo do Cenozóico, e as zonas topograficamente mais baixas sujeitas ao lento e estável soerguimento epirogénetico do Escudo Brasileiro ou aos abatimentos dos grábens regionais. De acordo com os autores este nível ocorre com destaque na região das cunhas tectônicas de Socorro e Guaxupé, estando associado a morros de vertentes convexo-côncavas e cristas de topos suavizados. Além disso, em topografias acima de $1360 \mathrm{~m}$ surgem níveis correlacionados a remanescentes da Superfície Sul-Americana soerguidos, assim como afirmado anteriormente por Saadi et al. (1998).

Ponçano \& Almeida, (1993) colocam que nessa região depósitos do final do Cretáceo e início do Paleógeno, mostram que a elaboração da superfície Japi não correspondem a um evento simples, já que a elaboração desse provável pediplano se teria dado pari passu ao vulcanismo e ao soerguimento crustal, que foi consequentemente acompanhado de falhamentos. Almeida e Carneiro (1998) apontam que a superfície Japi é Neocretácea, e de acordo com Zalán \& Oliveira (2005) ela teria aplainado e nivelado grande parte da região sudeste brasileira, ao final do Cretáceo, ao redor de 66-65 Ma, como demostra Riccomini et al.. (2004) a partir de datação de lava alcalina derramada sobre a superfície (Grabén da Guanabara), pelo método ${ }^{40} \mathrm{Ar} /{ }^{39} \mathrm{Ar}$.

\section{Metodologia}

Em duas etapas de campo foram coletadas 26 amostras, sendo que apenas 13 amostras continham apatitas suficiente para análise de TFA. As amostras foram coletadas em diferentes níveis topográficos tanto 


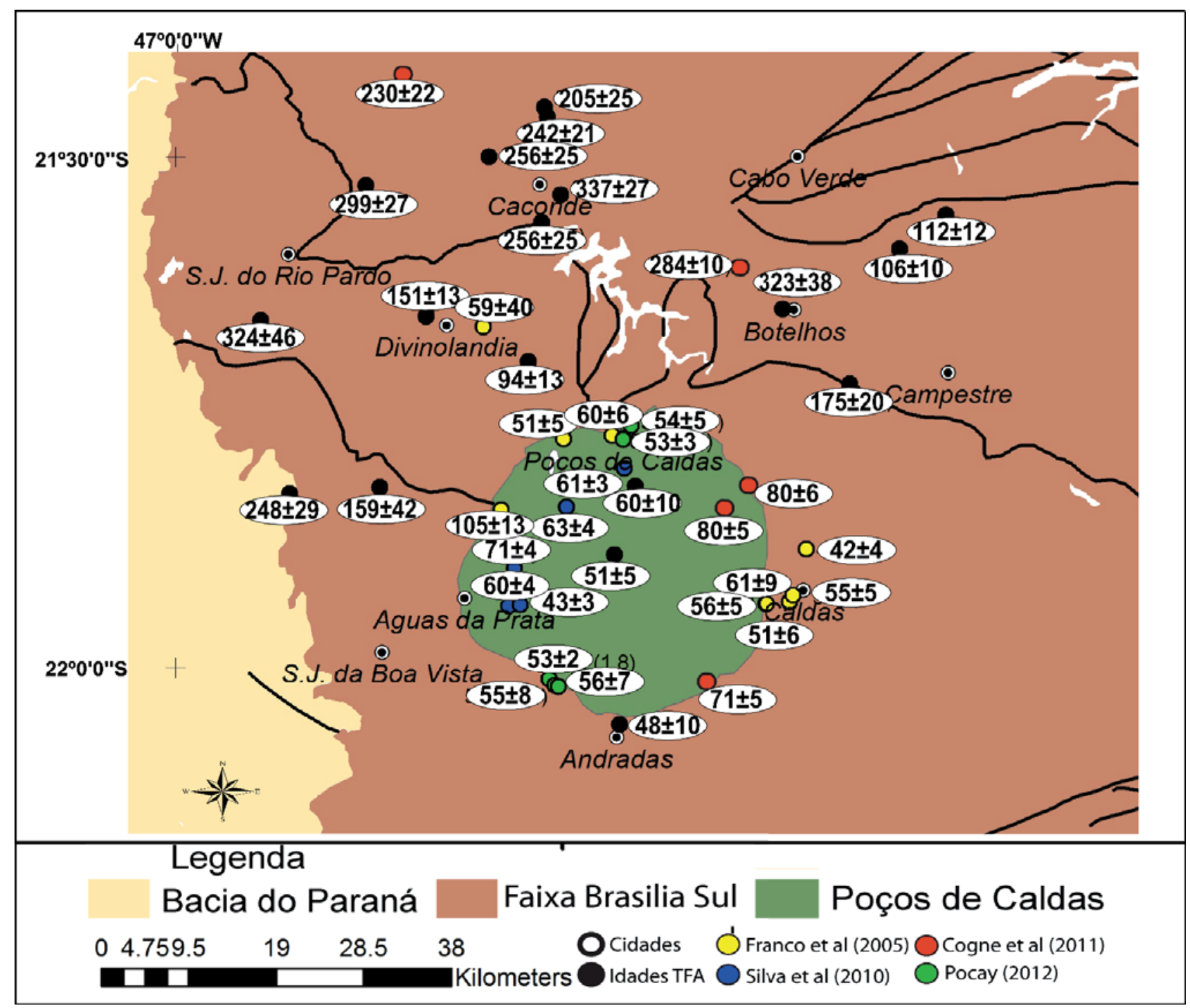

Figura 2 - Mapa Geológico com e distribuição das amostras (*amostra coletada em deposito sedimentar)

na região da intrusão alcalina como também na região do escudo cristalino. Foram ainda analisadas 27 amostras da literatura (GODOY, 2003; FRANCO et al. 2005; DORANTI et al. 2008; SILVA, 2010; COGNÉ 2011; POCAY, 2012; SOUZA 2013). Dessas 27 amostras, 6 possuem além dos dados e TFA, dados de (U-Th) He em apatitas (SILVA, 2010; COGNÉ et al. 2011). A litologia das amostras é principalmente de rochas pré-cambrianas (gnaisse, granito e charnokito) e rochas alcalinas (nephelina-sienito e fonolitos). Para a separação mineral, foram obedecidos os critérios descritos por Donelick et al. (2005). A concentração do material foi feita no Núcleo de Cronologia e Cronometria da UNESP de Rio Claro. Já os procedimentos de preparação para envio das amostras ao reactor nuclear foram feitos no Laboratório de Termocronologia e Arqueometria da
Universidade de Heidelberg, Alemanha. Foi utilizado o método do detector externo descrito por Wagner and Van den haute, 1992. As amostras foram irradiadas no reator FRM II na cidade de Munique, Alemanha. Nas amostras irradiadas foram incluídos três vidros dosimetros (CN5) com conhecida concentração de uranio da apatita Durango.

A análise microscópica dos traços (contagem e medida do comprimento dos traços) também foi realizada na Universidade de Heidelberg, Alemanha. Os valores de $\zeta$ obtidos foram $326 \pm 11$ e $342,82 \pm 30$ para o CN5 e a idade foi calculada utilizando o programa TRACKKEY (DUNKL, 2002). As histórias térmicas foram obtidas a partir do programa HEFTY (KETCHAM, 2005). 
As histórias térmicas foram obtidas usando o programa HeFTy (KETCHAM, 2005) nas amostras que foram encontrados traços confinados suficientes (aproximadamente 50 por amostra). Apenas uma história térmica foi obtida para a região do Maciço Alcalino de Poços de Caldas (TF-1076) e três histórias para a região cristalina a norte de Poços de Caldas (TF-667, TF-668 e TF-702).

\section{Modelagem termocinemática 3D (PECUBE)}

A quantificação dos processos que levam a paisagem se adaptarem as mudanças tectônicas e as variações do fluxo de calor tem sido objeto de estudos em muitas pesquisas aumentando o conhecimento sobre a relação entre isotermas e a superfície topográfica, o que possibilita melhores interpretações de dados termocronológicos (BRAUN, 2002a;2003;2005). Para alcançar esses resultados é necessário o uso de modelos numéricos para resolver um conjunto de equações que descrevem os processos físicos. Essas equações podem ser resolvidas a partir de um método numérico, baseado num código elemento-finito criado por Jean Braun chamado PECUBE (BRAUN, 2003; 2005). Esse código foi desenvolvido basicamente para solucionar a equação do fluxo de calor em três dimensões numa região da crosta terrestre que tenha sido exumada e caracterizada por uma mudança na amplitude da superfície topográfica (BRAUN 2003; 2005).

Todos os parâmetros são definidos, incluindo a taxa de exumação e a geometria da superfície topográfica em um número finito de vezes no passado. Entre essas vezes, se assume que a topografia muda linearmente de uma configuração para a próxima. Segundo Braun (2005), o método possui excelente acurácia, é estável e eficiente, sendo descrito em Braun (2003). O Pecube tem sido desenvolvido no sistema computacional ForTran90, onde o usuário pode descrever o problema de duas maneiras: através de uma entrada detalhada ASCII (Pecube. in) ou modificando uma das sub-rotinas (create_pecube_in.90) que irá criar um arquivo de saída.

Esse programa tem sido utilizado em várias regiões, sendo que a mais estudada foi a de Sierra Nevada, na Califórnia. Sendo que o objetivo inicial foi estudar a evolução da estrutura termal abaixo da superfície topográfica do King Canyon, onde já havia dados de termocronologia por (U-Th)/He (HOUSE, et. al. 1998; BRAUN et al.. 2003). Essa modelagem termocinemáti- ca auxilia na interpretação dos dados termocronológicos obtidos pela análise de traços de fissão e (U-Th)/He em apatitas e zircão, permitindo melhores resultados sobre a gênese e evolução da paisagem numa determinada região.

A modelagem termonicemática 3D realizada no programa PECUBE, levou em consideração diversos fatores, como descritos por Braun, (2003). Foram considerados parâmetros, obtidos a partir de dados da bibliografia (Araujo, 1980; Slavec et al..2004; Hanza et al.. 2005). A imagem DEM necessária, foi obtida no banco de dados de imagens SRTM do http://srtm. csi.cgiar.org/. A quantidade de cenários foi definida de acordo com a geologia e geomorfologia conhecida na região. Sendo que o período inicial da história a ser modelada foi escolhida de acordo com as idades de TFA mais antigas para cada região modelada. Foram modeladas duas áreas distintas devido à diferenças de idades, grau geotérmico e elevação topográfica de cada região. Assim a região foi subdividida: Maciço Alcalino de Poços de Caldas (MAPC) e Zona Cristalina do Norte (ZCN). A figura 6 a seguir mostra as áreas selecionadas e a distribuição das mostras.

\section{Apresentação dos Resultados}

\section{Análise de Traços de Fissão em Apatitas}

Foram analisadas 39 amostra de TFA distribuídas por toda a área de estudos incluindo as áreas interiores e exteriores ao MAPC (Figura 2). As idades obtidas no embasamento cristalino variam entre $\sim 340$ a $\sim 100 \mathrm{Ma}$ enquanto as obtidas no interior da intrusão variam entre $\sim 90$ a 42 Ma. Já as amostras restantes foram obtidas de diferentes publicações disponíveis (GODOY, 2003; FRANCO, 2003; FRANCO et al.., 2005; DORANTI, 2006; SILVA, 2010; COGNÉ et al. 2011; Souza 2013). Os parâmetros das amostras estão na tabela 1 a seguir:

O gráfico de Idade x Elevação (Figura 3) mostra três grupos principais de idades, o primeiro grupo com elevações entre 700 a $1000 \mathrm{~m}$ de altitude tem idades entre 250 a 350Ma. Enquanto que um segundo grupo, abrangendo elevações altimétricas entre 900 a 1200m possui idades entre 200 a 100Ma. Esses dois grupos de amostras correspondem à região cristalina da área de estudos enquanto o terceiro grupo de amostras pertencem à região do Maciço Alcalino de Poços de Caldas com idades entre 90 a 42Ma e elevações entre 900 a 1600m. 


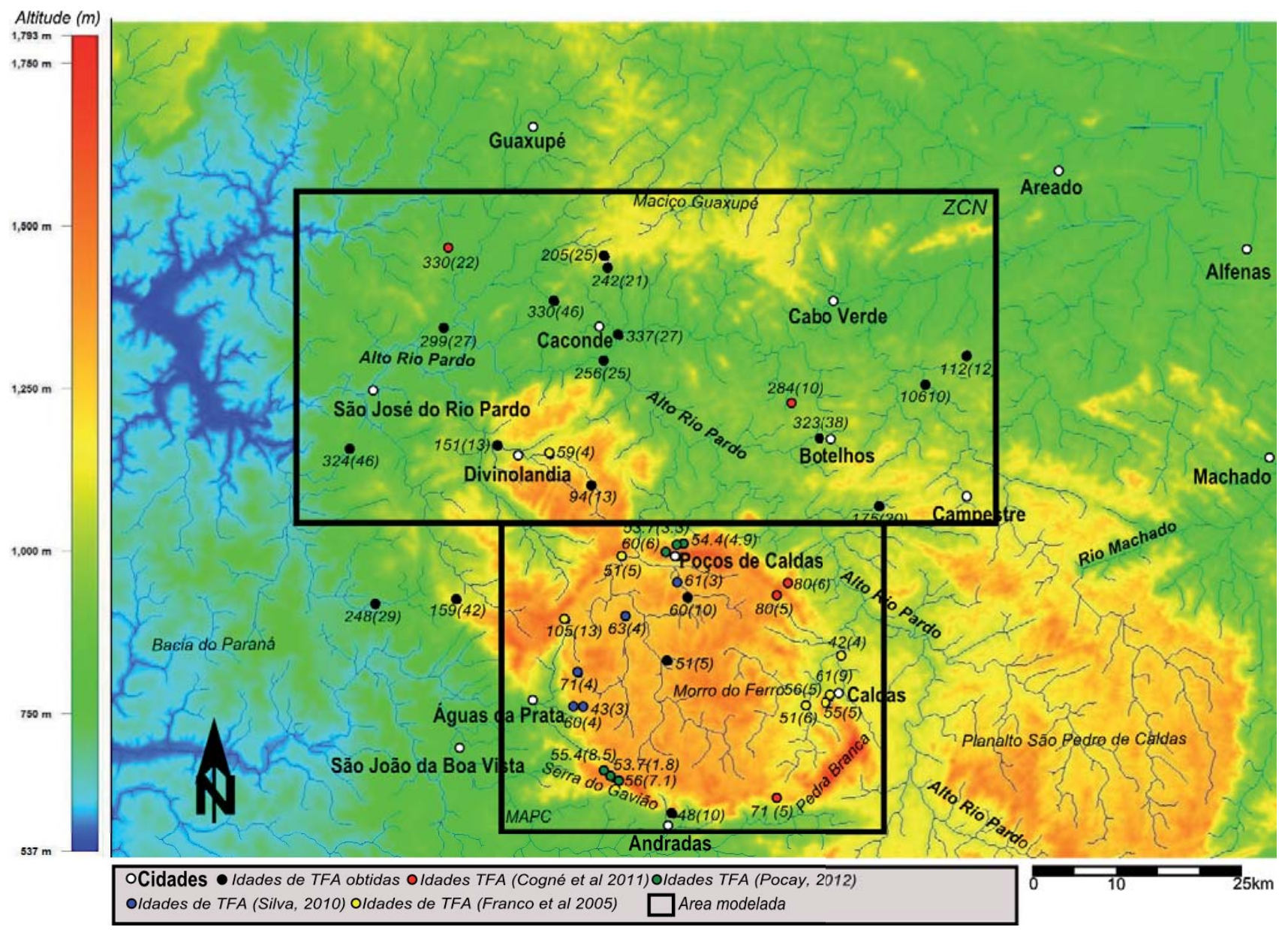

Figura 3 - Distribuição das amostras e recorte das areas selecionadas para modelagem.

As amostras do embasamento cristalino registram um resfriamento rápido iniciado por volta de $\sim 500$ a 400 $\mathrm{Ma}$ (entre $\sim 240^{\circ} \mathrm{C} \mathrm{a} \sim 60^{\circ} \mathrm{C}$ ) e posteriormente um longo período de estabilidade termal na faixa dos $\sim 60^{\circ} \mathrm{C}$ até aproximadamente $50 \mathrm{Ma}$; quando se inicia um resfriamento em $\sim 40^{\circ} \mathrm{C}$ (Figura 4).

Com relação à amostra da região do Maciço Alcalino (TF-1076), há resfriamento rápido por volta de $\sim 80 \mathrm{Ma}$, quando inicia uma estabilidade por volta dos $40^{\circ} \mathrm{C}$ até aproximadamente $50 \mathrm{Ma}$, quando ocorre um pequeno aquecimento, entre 40 e $75^{\circ} \mathrm{C}$ até $\sim 5 \mathrm{Ma}$, quando ocorre um novo resfriamento rápido até $\sim 20$ ${ }^{\circ} \mathrm{C}$ (Figura 5).

\section{Modelagem termocinemática 3D}

\section{Parâmetros para região do Maciço Alcalino de Poços de Caldas (MAPC)}

Foram considerados os seguintes parâmetros (que são exigidos pelo programa) para obtenção dos resulta- dos para a região do MAPC:

- Modelo de espessura crustal: $20 \mathrm{~km}$

- Número de pontos na direção vertical: 30 (resolução

- Difusividade Termal: 25km/Myr (Braun et al. 2005)

- Temperatura na base do modelo: $760^{\circ} \mathrm{C}$

- Taxa de lapso atmosférico: 0

- Produção de calor crustal: 4,25 C०/Km (Braun et al. 2005)

- Tempo de resposta erosional: 1000

- Número de etapas do cenário tectonomórfico: 3

- Início: $150 \mathrm{Ma}$

- $\quad 1^{\circ}$ Evento: $80 \mathrm{Ma}$

- $\quad 2^{\circ}$ Evento: $60 \mathrm{Ma}$

Para a região do MAPC (Figura 7) foram escolhidos tres periodos relacionados a eventos geologicos que possivelmente teriam influenciado à evolução geomorfica da região. Fori escolhido para inicio da modelagem evolutiva o periodo de 120 Ma por estar correlacionado 
Evolução do Relevo da Região do Planalto de Poços de Caldas (Sp/Mg) Baseado em Dados

Tabela 1 - Parâmetros físicos das amostras. U(std: quantidade do elemento U na amostra; n: numero de grãos utilizados; ps: densidade de traços espontâneos; Ns: número de traços espontâneos; pi: densidade de traços induzidos; Ni: número de traços induzidos; Chi-sq (\%): probabilidade de valores maiores.

\begin{tabular}{|c|c|c|c|c|c|c|c|c|c|c|c|}
\hline Amostras & U(std) & $\mathbf{n}$ & $\mathbf{L}$ & $\mathbf{L m}$ & $\rho s$ & Ns & $\rho \mathbf{i}$ & $\mathrm{Ni}$ & Chi-sq (\%) & $\begin{array}{c}\text { Idade } \\
\text { Central }\end{array}$ & Referência \\
\hline $\mathrm{TF}-134$ & $24.9(6.2)$ & 19 & N/D & N/D & 46.647 & 1424 & 28.139 & 859 & 98.5 & $337(27)$ & atual \\
\hline $\mathrm{TF}-135$ & $27.1(13.3)$ & 9 & N/D & $\mathrm{N} / \mathrm{D}$ & 37.342 & 470 & 29.383 & 380 & 21.5 & $256(25)$ & atual \\
\hline $\mathrm{TF}-311$ & $\mathrm{~N} / \mathrm{D}$ & 27 & N/D & N/D & $\mathrm{N} / \mathrm{D}$ & 308 & $\mathrm{~N} / \mathrm{D}$ & 304 & $\mathrm{~N} / \mathrm{D}$ & $60(6)$ & $\begin{array}{l}\text { Godoy } \\
(2003)\end{array}$ \\
\hline $\mathrm{TF}-313$ & $9.6(4.2)$ & 17 & N/D & $\mathrm{N} / \mathrm{D}$ & 3.143 & 82 & 10.197 & 266 & 26.1 & $61(9)$ & atual \\
\hline $\mathrm{TF}-315$ & $\mathrm{~N} / \mathrm{D}$ & 8 & $\mathrm{~N} / \mathrm{D}$ & $\mathrm{N} / \mathrm{D}$ & $\mathrm{N} / \mathrm{D}$ & 51 & $\mathrm{~N} / \mathrm{D}$ & 63 & N/D & $51(6)$ & $\begin{array}{l}\text { Godoy } \\
(2003)\end{array}$ \\
\hline $\mathrm{TF}-502$ & N/D & 79 & $\mathrm{~N} / \mathrm{D}$ & $\mathrm{N} / \mathrm{D}$ & $\mathrm{N} / \mathrm{D}$ & 246 & $\mathrm{~N} / \mathrm{D}$ & 261 & $\mathrm{~N} / \mathrm{D}$ & $51(5)$ & $\begin{array}{c}\text { Franco et al. } \\
(2005)\end{array}$ \\
\hline $\mathrm{TF}-503$ & $\mathrm{~N} / \mathrm{D}$ & 82 & $\mathrm{~N} / \mathrm{D}$ & N/D & $\mathrm{N} / \mathrm{D}$ & 963 & $\mathrm{~N} / \mathrm{D}$ & 752 & $\mathrm{~N} / \mathrm{D}$ & $59(4)$ & $\begin{array}{c}\text { Franco et al. } \\
(2005)\end{array}$ \\
\hline $\mathrm{TF}-505$ & N/D & 74 & $\mathrm{~N} / \mathrm{D}$ & $\mathrm{N} / \mathrm{D}$ & $\mathrm{N} / \mathrm{D}$ & 704 & $\mathrm{~N} / \mathrm{D}$ & 841 & N/D & $42(4)$ & $\begin{array}{c}\text { Franco et al. } \\
(2005)\end{array}$ \\
\hline $\mathrm{TF}-506$ & N/D & 88 & $\mathrm{~N} / \mathrm{D}$ & $\mathrm{N} / \mathrm{D}$ & $\mathrm{N} / \mathrm{D}$ & 419 & $\mathrm{~N} / \mathrm{D}$ & 377 & $\mathrm{~N} / \mathrm{D}$ & $55(5)$ & $\begin{array}{c}\text { Franco et al. } \\
(2005)\end{array}$ \\
\hline $\mathrm{TF}-507$ & N/D & 98 & $\mathrm{~N} / \mathrm{D}$ & $\mathrm{N} / \mathrm{D}$ & $\mathrm{N} / \mathrm{D}$ & 824 & $\mathrm{~N} / \mathrm{D}$ & 728 & $\mathrm{~N} / \mathrm{D}$ & $56(5)$ & $\begin{array}{c}\text { Franco et al. } \\
(2005)\end{array}$ \\
\hline $\mathrm{TF}-508$ & $\mathrm{~N} / \mathrm{D}$ & 67 & N/D & $\mathrm{N} / \mathrm{D}$ & $\mathrm{N} / \mathrm{D}$ & 444 & $\mathrm{~N} / \mathrm{D}$ & 487 & $\mathrm{~N} / \mathrm{D}$ & $46(4)$ & $\begin{array}{c}\text { Franco et al. } \\
(2005)\end{array}$ \\
\hline $\mathrm{TF}-556$ & $25.0(13.5)$ & 17 & N/D & $\mathrm{N} / \mathrm{D}$ & 31.473 & 1138 & 26.522 & 959 & 0 & $248(29)$ & atual \\
\hline $\mathrm{TF}-557$ & $20.3(10.4)$ & 5 & N/D & N/D & 18.928 & 205 & 22.067 & 239 & 0 & $159(42)$ & atual \\
\hline $\mathrm{TF}-558$ & N/D & 19 & $\mathrm{~N} / \mathrm{D}$ & $\mathrm{N} / \mathrm{D}$ & $\mathrm{N} / \mathrm{D}$ & 89 & $\mathrm{~N} / \mathrm{D}$ & 39 & $\mathrm{~N} / \mathrm{D}$ & $105(13)$ & $\begin{array}{l}\text { Godoy } \\
(2003)\end{array}$ \\
\hline $\mathrm{TF}-559$ & $17.1(9.9)$ & 20 & N/D & $\mathrm{N} / \mathrm{D}$ & 14.981 & 532 & 16.304 & 579 & 0.2 & $175(20)$ & atual \\
\hline $\mathrm{TF}-667$ & $26.7(18.7)$ & 17 & 50 & 11.22 & 40.752 & 1342 & 23.079 & 760 & 0 & $324(46)$ & atual \\
\hline $\mathrm{TF}-668$ & $18.6(8.6)$ & 19 & 50 & 11.97 & 28.243 & 1326 & 17.828 & 837 & 1.5 & $299(27)$ & atual \\
\hline $\mathrm{TF}-700$ & $12.4(7.1)$ & 17 & 50 & 11.53 & 21.010 & 972 & 13.423 & 621 & 0 & $330(46)$ & atual \\
\hline $\mathrm{TF}-702$ & $30.7(10.4)$ & 18 & N/D & N/D & 39.914 & 1562 & 31.712 & 1241 & 1 & $242(21)$ & atual \\
\hline $\mathrm{TF}-703$ & $44.6(9.8)$ & 12 & N/D & $\mathrm{N} / \mathrm{D}$ & 51.829 & 1082 & 47.087 & 983 & 0 & $205(25)$ & atual \\
\hline $\mathrm{TF}-712$ & N/D & 36 & N/D & N/D & N/D & 660 & $\mathrm{~N} / \mathrm{D}$ & 222 & $\mathrm{~N} / \mathrm{D}$ & $112(12)$ & $\begin{array}{l}\text { Doranti et } \\
\text { al. }(2008)\end{array}$ \\
\hline $\mathrm{TF}-713$ & N/D & 25 & N/D & N/D & $\mathrm{N} / \mathrm{D}$ & 445 & N/D & 174 & $\mathrm{~N} / \mathrm{D}$ & $106(10)$ & $\begin{array}{l}\text { Doranti et } \\
\text { al. }(2008)\end{array}$ \\
\hline $\mathrm{TF}-714$ & $9.7(7.4)$ & 20 & $\mathrm{~N} / \mathrm{D}$ & $\mathrm{N} / \mathrm{D}$ & 15.444 & 626 & 9.991 & 405 & 0.2 & $323(38)$ & atual \\
\hline TF-1074 & $11.9(4.9)$ & 8 & $\mathrm{~N} / \mathrm{D}$ & $\mathrm{N} / \mathrm{D}$ & 3.112 & 38 & 13.922 & 170 & 24.9 & $48(10)$ & atual \\
\hline TF-1076 & $30.4(10.9)$ & 20 & 24 & 10.08 & 8.144 & 328 & 32.253 & 1299 & 14.9 & $51(5)$ & atual \\
\hline TF-1077 & $23.1(10.2)$ & 7 & N/D & $\mathrm{N} / \mathrm{D}$ & 7.104 & 76 & 21.313 & 228 & 20.62 & $60(10)$ & atual \\
\hline TF-1079 & $15.6(8)$ & 18 & $\mathrm{~N} / \mathrm{D}$ & $\mathrm{N} / \mathrm{D}$ & 8.356 & 348 & 16.784 & 699 & 0 & $94(13)$ & atual \\
\hline TF-1080 & $32.8(13.5)$ & 19 & 22 & 11.09 & 25.604 & 782 & 31.595 & 965 & 28.6 & 151(13) & atual \\
\hline
\end{tabular}


Doranti-Tiritan C. et al.

\begin{tabular}{|c|c|c|c|c|c|c|c|c|c|c|c|}
\hline TF-1180 & 48.13 & 61 & N/D & N/D & 14.946 & 1245 & 36.146 & 3011 & 71.19 & $53.7(1.8)$ & $\begin{array}{l}\text { Pocay } \\
(2012)\end{array}$ \\
\hline TF-1182 & 9.72 & 15 & $\mathrm{~N} / \mathrm{D}$ & N/D & 3.352 & 61 & 7.857 & 143 & 72.64 & $55.4(8.5)$ & $\begin{array}{l}\text { Pocay } \\
(2012)\end{array}$ \\
\hline TF-1183 & 20.71 & 16 & N/D & N/D & 6.885 & 126 & 15.628 & 286 & 37.79 & $56(7.1)$ & $\begin{array}{l}\text { Pocay } \\
(2012)\end{array}$ \\
\hline TF-1186 & 34.17 & 27 & N/D & N/D & 10.641 & 382 & 25.738 & 924 & 99.15 & $53.7(3.3)$ & $\begin{array}{l}\text { Pocay } \\
(2012)\end{array}$ \\
\hline TF-1187 & 23.6 & 30 & N/D & $\mathrm{N} / \mathrm{D}$ & 7.542 & 224 & 18.552 & 551 & 19.14 & $54.4(4.9)$ & $\begin{array}{l}\text { Pocay } \\
(2012)\end{array}$ \\
\hline TF-1188 & 25.02 & 16 & N/D & N/D & 9.579 & 182 & 14.579 & 277 & 6.25 & $76.8(10.9)$ & $\begin{array}{l}\text { Pocay } \\
(2012)\end{array}$ \\
\hline TF-1207 & $19.3(6.0)$ & 10 & $\mathrm{~N} / \mathrm{D}$ & $\mathrm{N} / \mathrm{D}$ & 3.713 & 282 & 13.336 & 1013 & 42.7 & $43(3)$ & Silva (2010) \\
\hline TF-1208 & $15.1(17.7)$ & 21 & N/D & $\mathrm{N} / \mathrm{D}$ & 4.264 & 748 & 10.751 & 1886 & 43.5 & $60(4)$ & Silva (2010) \\
\hline TF-1209 & $15.3(4.9)$ & 15 & $\mathrm{~N} / \mathrm{D}$ & N/D & 5.184 & 521 & 11.661 & 1172 & 81.5 & 71(4) & Silva (2010) \\
\hline TF-1211 & $21.3(8.1)$ & 20 & $\mathrm{~N} / \mathrm{D}$ & $\mathrm{N} / \mathrm{D}$ & 6.778 & 1217 & 17.142 & 3078 & 90.7 & $61(3)$ & Silva (2010) \\
\hline TF-1212 & $15.9(10.2)$ & 13 & $\mathrm{~N} / \mathrm{D}$ & N/D & 4.467 & 418 & 11.06 & 1035 & 66 & $63(4)$ & Silva (2010) \\
\hline BRA824 & 12.1 & $\mathrm{~N} / \mathrm{D}$ & $\mathrm{N} / \mathrm{D}$ & 13.06 & N/D & N/D & N/D & N/D & N/D & $330.3(22)$ & $\begin{array}{l}\text { Cogné } \\
(2011)\end{array}$ \\
\hline BRA827 & 39.9 & N/D & $\mathrm{N} / \mathrm{D}$ & 11.49 & $\mathrm{~N} / \mathrm{D}$ & N/D & N/D & N/D & N/D & $284.9(10)$ & $\begin{array}{l}\text { Cogné } \\
(2011)\end{array}$ \\
\hline BRA829 & 15.5 & N/D & $\mathrm{N} / \mathrm{D}$ & 13.83 & N/D & $\mathrm{N} / \mathrm{D}$ & N/D & $\mathrm{N} / \mathrm{D}$ & N/D & $80.1(5)$ & $\begin{array}{l}\text { Cogné } \\
(2011)\end{array}$ \\
\hline BRA831 & 10.5 & N/D & $\mathrm{N} / \mathrm{D}$ & 13.54 & $\mathrm{~N} / \mathrm{D}$ & N/D & N/D & N/D & N/D & $81(6)$ & $\begin{array}{l}\text { Cogné } \\
(2011)\end{array}$ \\
\hline BRA834 & 4.2 & N/D & $\mathrm{N} / \mathrm{D}$ & 14.67 & N/D & N/D & N/D & $\mathrm{N} / \mathrm{D}$ & N/D & 71.1 & $\begin{array}{l}\text { Cogné } \\
(2011)\end{array}$ \\
\hline
\end{tabular}

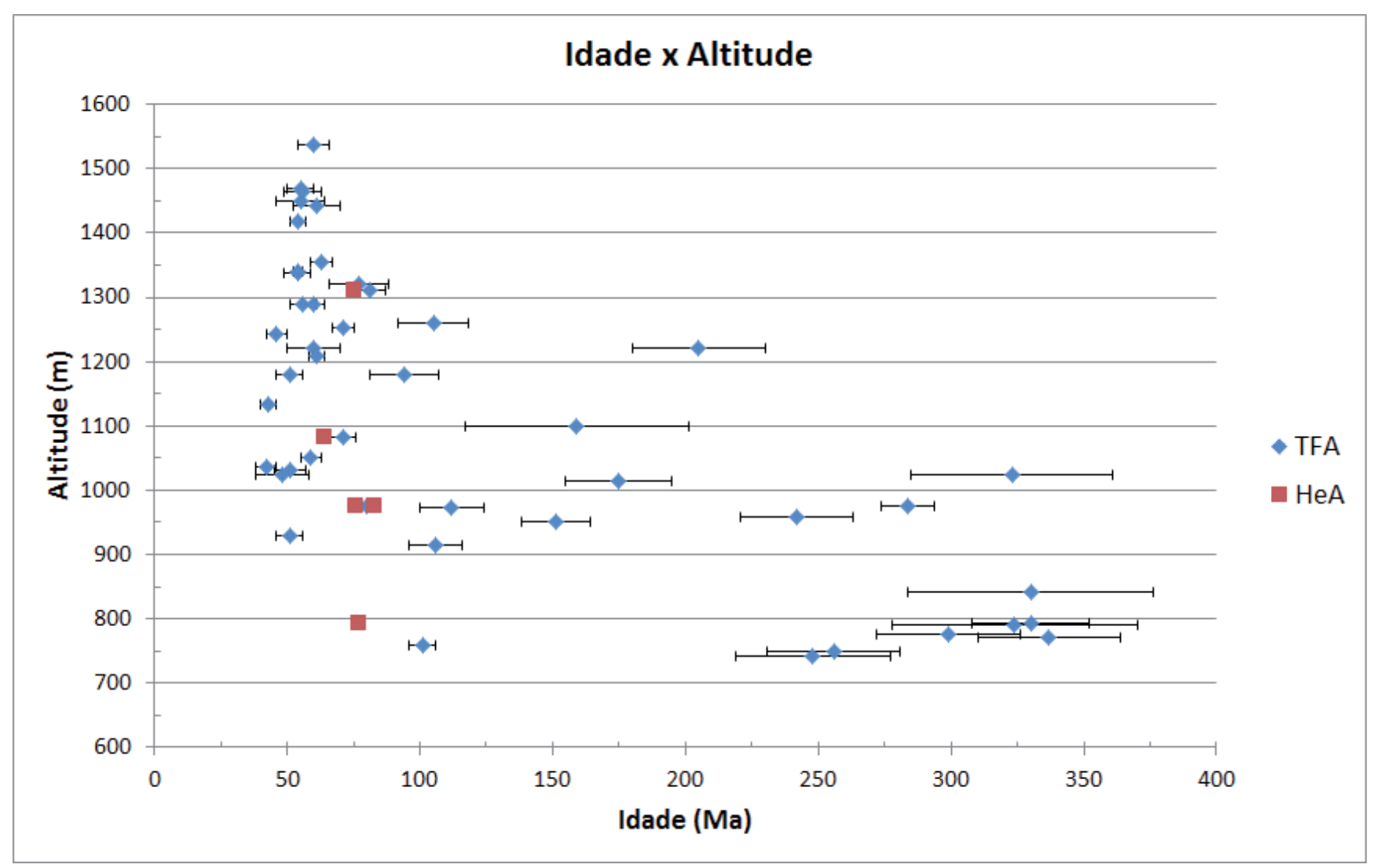

Figura 4 - Idades de Traços de Fissão em Apatitas e (U-Th)/He em apatitas 
Evolução do Relevo da Região do Planalto de Poços de Caldas (Sp/Mg) Baseado em Dados
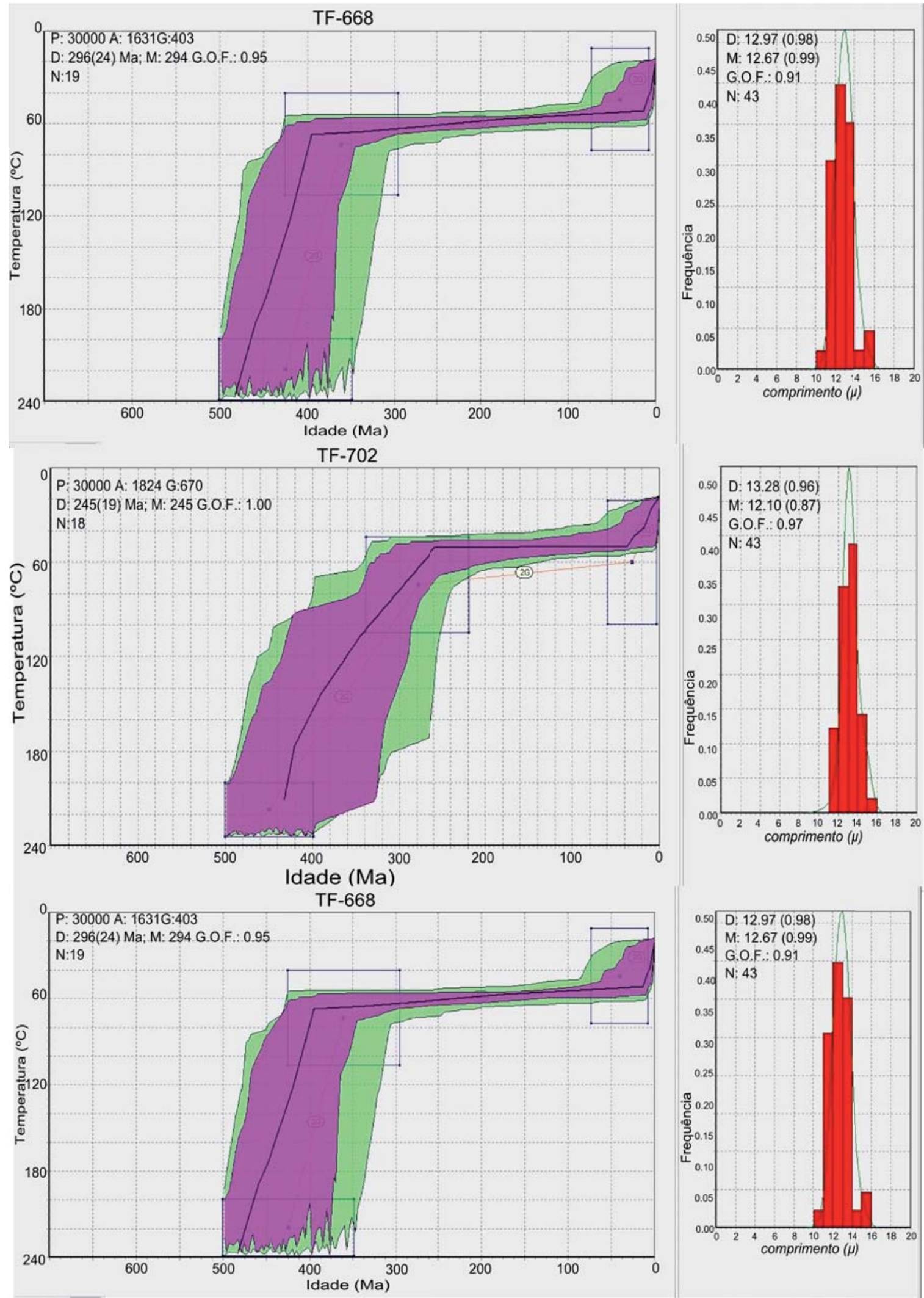

Figura 5 - Modelagem inversa e respectivo histograma de comprimentos das amostras TF-667;TF-668;TF-702. P: número de the trajetórias; A: trajetórias aceitáveis (verde); G: trajetórias ótimas (rosa); Parâmetros do modelo: D: idade TFA calculada; M: Idade TFA simulada; G..O.F.: melhor ajuste. N: número de grãos da amostra; Parametros do Histograma: média do comprimento medido; M: média do comprimento do modelo; G..O.F.: melhor ajuste; N: número de traços confinados medidos. 


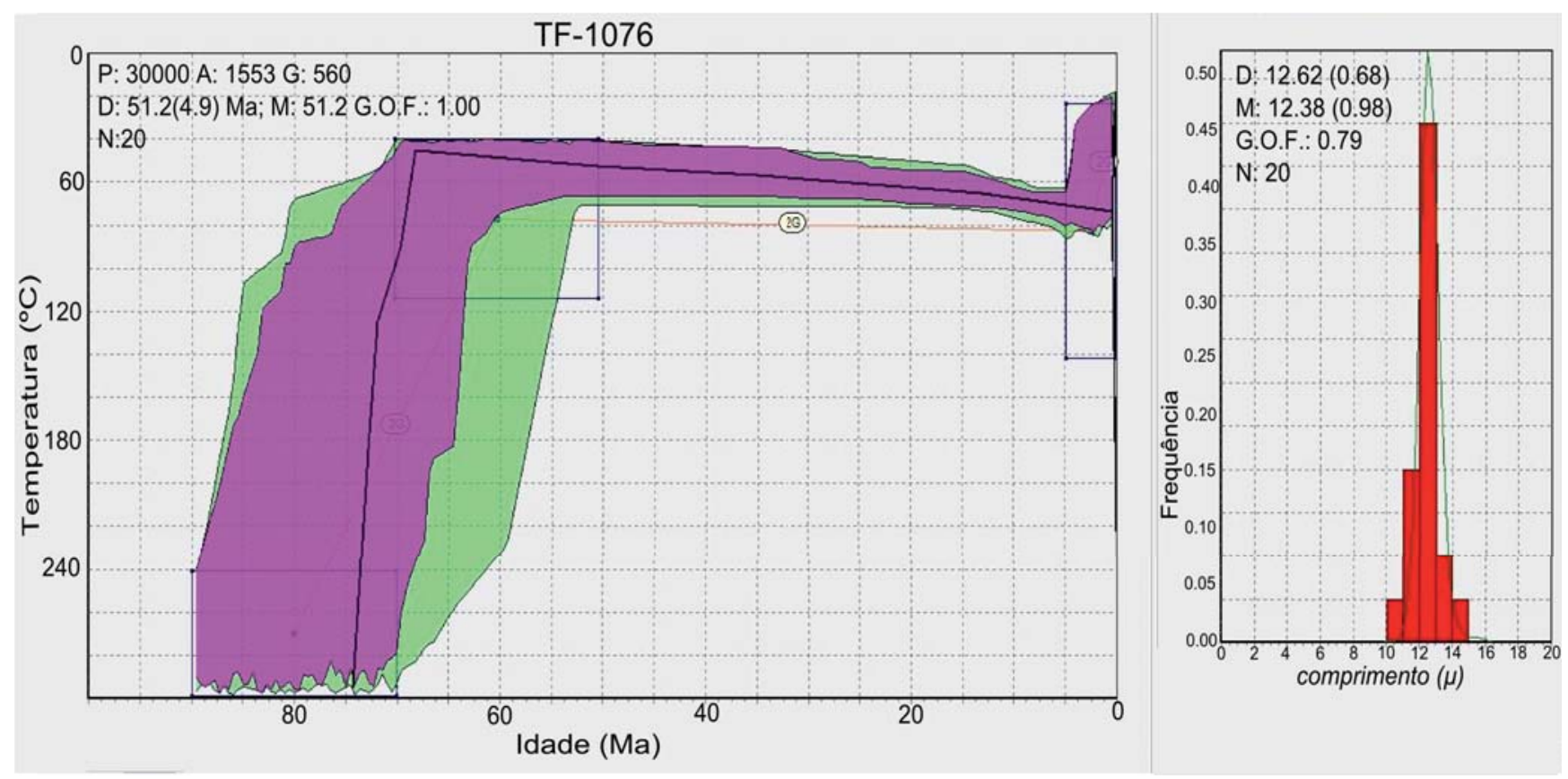

Figura 6 - Modelagem inversa e respectivo histograma de comprimentos das amostras TF-1076. P: numero de the trajetórias; A: trajetórias aceitáveis (verde); G: trajetórias ótimas (rosa); Parâmetros do modelo: D: idade TFA calculada; M: Idade TFA simulada; G..O.F.: melhor ajuste. N: número de grãos da amostra; Parametros do Histograma: média do comprimento medido; M: média do comprimento do modelo; G..O.F.: melhor ajuste; N: número de traços confinados medidos

com o periodo pós abertura continental. O reusltado mostra que nesse periodo às taxas de exumação seriam nulas em praticamente toda a região. $\mathrm{O}$ segundo periodo escolhido é de 80 Ma por estar correlacionado com a idade da intrusão alcalina de Poços de Caldas. Nessa época muito provavelmente, a superficie topográfica juntamente com a isoterma estariam mais elevadas e a taxa de exumação para essa época seria entre zero nas regiões menos elevadas topograficamente e valores negativos nas regiões mais elevadas. Os valores negativos indicam que na região o soerguimento da superfície foi maior que a erosão.

Para os dias atuais a modelagem sugere que as taxas de exumação seriam positivas com uma variação entre 0,016 a $0,019 \mathrm{~km} / \mathrm{Ma}$ nas areas mais elevadas, e completamente nulas areas mais rebaixadas.

\section{Parâmetros para Região da Zona Cristalina do Norte}

Foram considerados os seguintes parâmetros para obtenção dos resultados para a Zona Cristalina do Norte:

Parâmetros termais:

- Modelo de espessura crustal: $30 \mathrm{~km}$
- Número de pontos na direção vertical: 30

- Difusividade Termal: 25km/Ma (Braun et al. 2005)

- Temperatura na base do modelo: $300^{\circ} \mathrm{C}$

- Taxa de lapso atmosférico: 0

- Produção de calor crustal: 3,5 C\%/Km (Braun et al. 2005)

- Tempo de resposta erosional: 1000

- Número de etapas do cenário tectono-mórfico: 3

- Início: 300Ma

- $1^{\circ}$ Evento: $150 \mathrm{Ma}$

- $2^{\circ}$ Evento: $80 \mathrm{Ma}$

Para a ZCN (Figura 8) foi escolhido como periodo inicial a idade de 300 Ma por coincidir com a maioria das idades da região. Nesse período a topografia seria mais aplainada e as taxas de exumação seriam praticamente nulas. O segundo periodo seria $150 \mathrm{Ma}$ por ser proximo ao periodo em que houve a ruptura do continente Gondwana no sudeste do Brasil. Nesse periodo às taxas de exumação estariam proximas a zero nas regiões mais rebaixadas enquanto nas áreas mias elevadas os valores são negativos, porém insignificantes. 
Evolução do Relevo da Região do Planalto de Poços de Caldas (Sp/Mg) Baseado em Dados
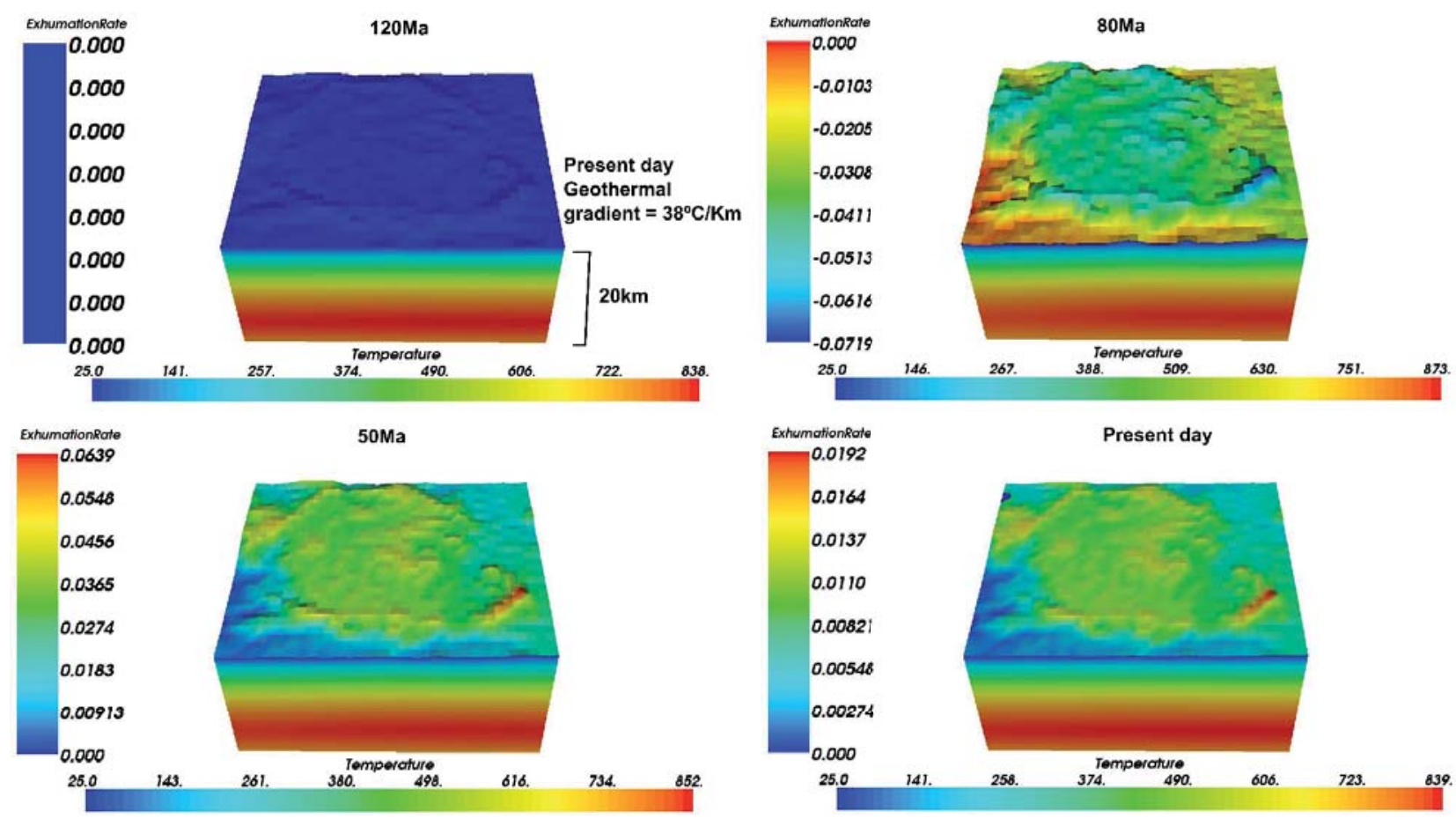

Figura 7 - Resultado da Modelagem Direta. Taxas de exumação pra Região do Maciço Alcalino de Poços de Caldas em 120, 80, 50Ma e presente

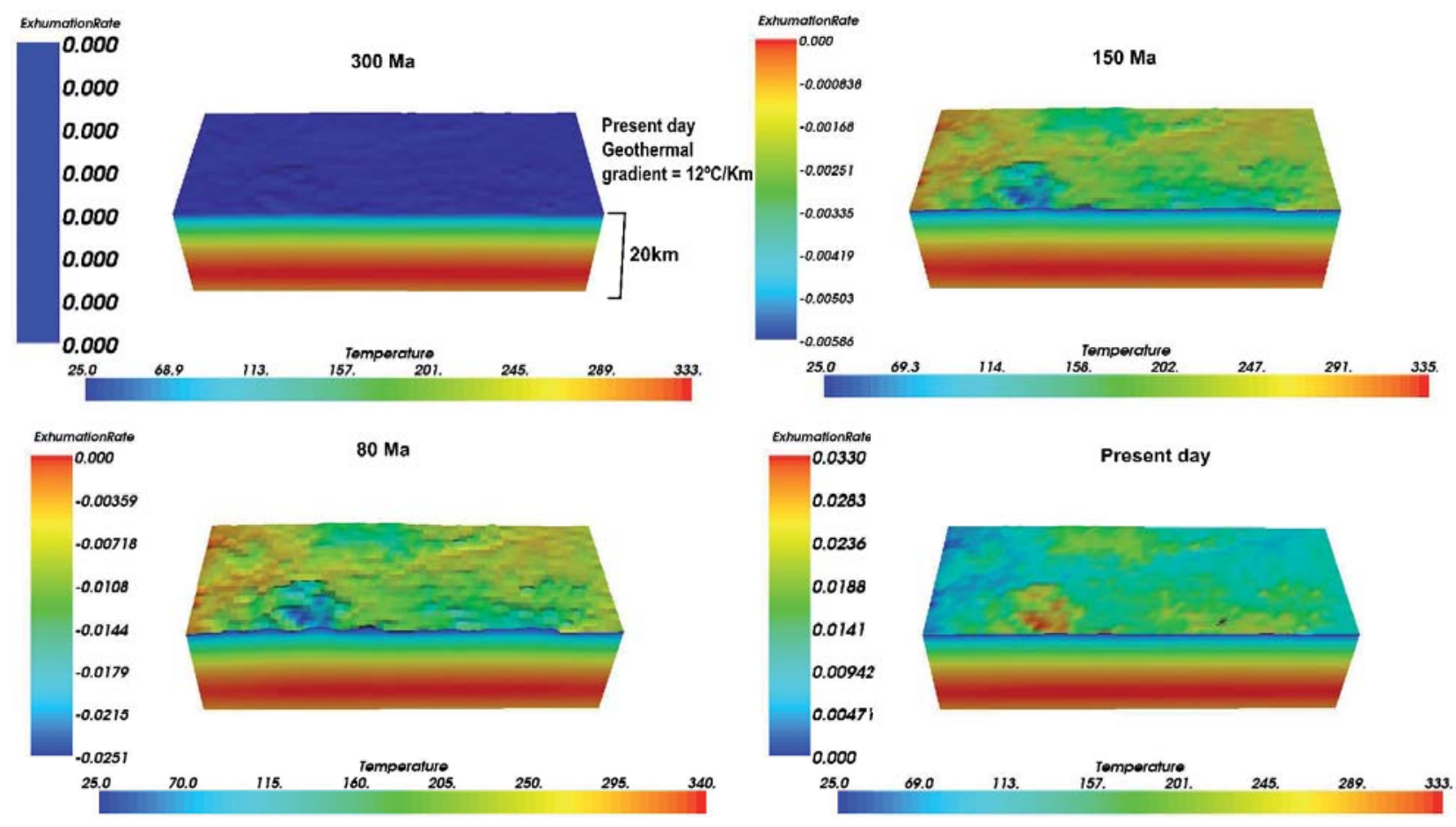

Figura 8 - Resultado da Modelagem Direta. Taxas de exumação pra Zona Cristalina Norte em 300, 150, 80Ma e presente 


\section{Doranti-Tiritan C. et al.}

O próximo período escolhido foi o de 80 Ma pois a região está relativamente próxima ao MAPC. As taxas também seriam negativas nas regiões mais elevadas mas os valores são mais expressivos do que os obtidos para o periodo de $150 \mathrm{Ma}$.

$\mathrm{O}$ resultado da modelagem para os dias atuais mostram valores muito proximos a zero, sendo que a variação também varia de acordo com a altitude, porém as areas mais elevadas a sul, estão muito próximas ao MAPC e provavelmente os parametros para essa parte da área seriam mais semelhantes ao escolhidos para área do maciço. Entretanto a versão do programa utilizada não permite que se faça uma distinção nos parâmetros.

No geral, observando que para os dias atuais, os resultados apresentam valores de exumação mais altos nas regiões topograficamente mais elevadas e valores negativos para mesma região em períodos em que a placa Sul-Americana sofria influência de eventos tectônicos e magmáticos Assim, que esses valores negativos estão indicando que a taxa de soerguimento é maior que a taxa de erosão. Logo, atualmente, como a região está relativamente estável as áreas topograficamente elevadas estão sofrendo maior atuação de processos erosivos enquanto as regiões mais baixas com valores de exumação próximos a zero são áreas de deposição/ sedimentação. Essa relação fica bem clara quando se observa as figuras 7 e 8 . Em $80 \mathrm{Ma}$, quando ocorre a intrusão alcalina de Poços de Caldas há um considerável aumento no grau geotérmico da região como também a elevação da topografia.

\section{Discussão}

Os dados de TFA permitiram obter uma estimativa sobre quais os principais processos foram mais atuantes na elaboração da paisagem residual no sudeste do Brasil a partir do Carbonífero. O gráfico de idade vs elevação (Figura 9) mostra duas retas positivas formadas por idades de amostras do embasamento cristalino que vão do Carbonífero ao Permiano. A inclinação positiva da reta indica que as idades mais antigas estão no topo enquanto as idades mais novas estão na base. Ela indica assim predomínio da atuação de processos erosivos em relação à tectônica. De acordo com Torquato \& Cordani (1981), durante esse período ambos continentes Africano e Sul Americano estavam cobertos pela glaciação continental, podendo ser comprovada pela estratigrafia das Bacias do Paraná e Karoo que apresentam similaridades em sua fauna e flora nesse período

De acordo com Visser (1987) o gelo foi capaz de erodir a paisagem e depositar os fragmentos de sedimentos inconsolidados como pode ser visto principalmente na Bacia de Karoo no continente africano. Ab'Saber (2000) aponta que durante esse período glacial mais de $1000 \mathrm{~m}$ de sedimentos foram acumulados e os glaciais seguiram do nordeste e leste do paleo-domo, mostrando então um relevo rebaixado sob um processo contínuo de aplanação.

Essa região apresenta os menores valores de gradiente geotérmico mostrando que não há nenhum tipo de alçamento térmico na região, mesmo estando próximo ao maciço alcalino de Poços de Caldas. As histórias termicas das amostras registram estabilidade termal por volta dos $60^{\circ} \mathrm{C}$ entre o Paleozóico e o Mesozóico e resfriamento rápido no inicio do cenozóico, esse resultado é semelhante ao de Cogné et al. (2011), que coloca que as antigas idades e a longa média dos comprimentos dos traços $(\sim 13 \mu)$ sugere que as amostras teriam ficado durante um longo periodo de tempo em baixa temperaturas $\left(\sim 60^{\circ} \mathrm{C}\right)$. Suas idades de $(\mathrm{U}-\mathrm{Th}) / \mathrm{He}$ sugerem um resfriamento entre o final do Cretáceo e inicio do Paleógeno, assim como nas histórias térmicas aqui apresentadas.

O gráfico mostra uma quebra na curva em 250Ma, período em que ocorre a orogenia Cabo-Laventana (TANKARD et al. 1995). Essa orogenia foi associada com a convergência ao longo da borda sul do Gondwana Oeste (COBBOLD et al. 1992) e relacionada à propragação de diversos esforços ao longo do continente, sendo responsável pelo soerguimento e pela denudação impulsionada pela deformação tranpressiva ao longo das zonas de cisalhamento Precambrianas. Riccomini et al. (2005) relaciona as deformações estruturais sin-sedimentares da borda leste da Bacia do Paraná à reativação tectônica da Zona de Cisalhamento Ouro Fino-Jacutinga durante essa orogenia. Esse evento é ainda correlacionado com as antigas idades de TFA registradas na Serra da Bocaina (Serra do Mar) (HIRUMA et al., 2010; Siqueira-Ribeiro et al., 2011) e com o aumento das taxas de erosão nesse período na região Sul do Brasil (FRANCO-MAGALHÃES et al. 2010; KARL et al. 2013).

Uma nova quebra positiva aparece no gráfico idade x elevação entre 200 e 150Ma (Figura 9). Esse período coincide com o período chamado por Almeida 


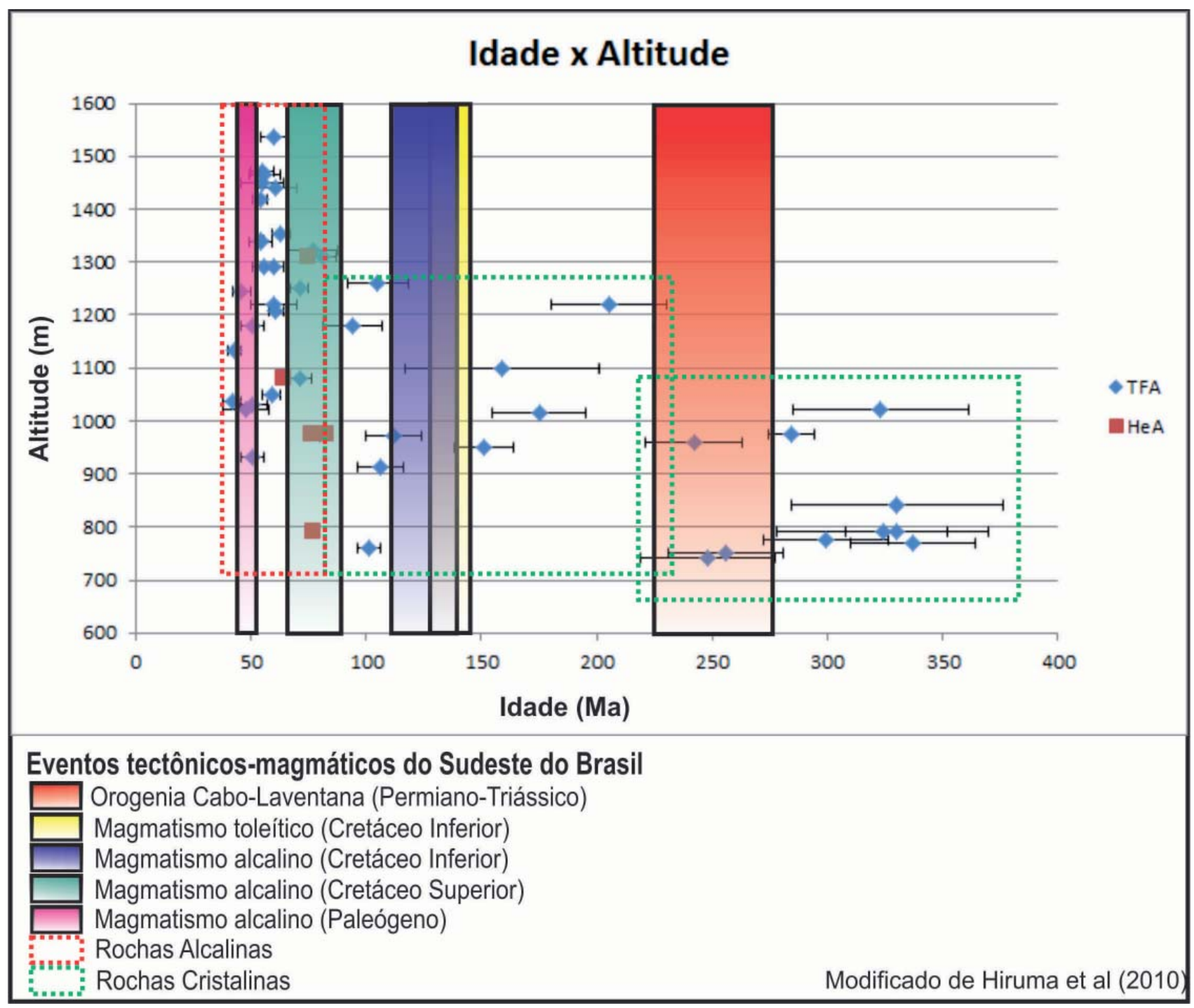

Figura 9 - Gráfico de Idade x Elevação (Traços de Fissão e (U-Th)He em Apatitas).

(1966) de "Estágio Estável” da plataforma Sul Americana. Segundo o autor nesse período as condições climáticas predominantes eram extremamente quentes e úmidas não havendo indícios de glaciações, orogenia ou mesmo fortes atividades tectônicas. Nesse período, grande parte do continente experimentou ampla estabilidade morfológica (RABASSA et al.. 2010)

As condições de estabilidade e intemperismo químico levaram a uma paisagem senil e plana que pode estar relacionada à superfície Gondwana (KING, 1956; 1976). Fairbridge (1968) definiu o conceito de "paisagem gondwana" como sendo uma "paisagem ancestral" que seria composta por uma "série de remanescentes" registrando traços de antigos episódios de aplainamento durante o mesozoico superior. De acordo com Rabassa et al.. (2010), esse processo foi denominado de "Ciclo erosivo Gondwana" nos continentes do hemisfério Sul, ocorrendo principalmente em áreas cratônicas da Austrália, Sul do continente Africano e America do Sul.

No final do Jurassico inicia-se os eventos tectono-magmaticos que levaram a ruptura do continente Gondwana (SCHOBBENHAUS et al. 1989). Por volta de $132 \mathrm{Ma}$ ocorre um intenso magmatismo toleítico na região Sul e Sudeste do Brasil (MARQUES \& ERNESTO, 2004). Almeida (2000) também concorda que os primeiros eventos magmáticos que precederam a abertura continental datam do final do periodo Jurássico, sendo que o magmatismo Serra Geral inicia-se no Cretáceo Inferior. Observa-se no gráfico da figura 9 que o limite entre o Cretáce Inferior e Superior há um novo trend negativo que pode estar relacionado com esses events como pode ser confirmado por outros tra- 
balhos nas regiões Sul e Sudeste do Brasil (FRANCO et al. 2005; DORANTI et al. 2008; Silva et al. 2011; COGNÉ et al. 2011).

No Cretáceo Superior a paisagem é marcada por processos de aquecimento entre 90 e 60Ma (HACKSPACHER et al., 2007). Segundo os autores, a elevação das isotermas foram registradas pelo método de TFA e estariam indicando um intenso soerguimento da Plataforma Sul Americana, estando associadas principalmente a atuação de alçamento de plumas mantélicas e afinamento crustal que causaram anomalias térmicas devido a entrada de magma em sub-superfície, relacionadas ao magmatismo alcalino.

Historias térmicas obtidas por Silva et al. (2011) revelam que um rápido resfriamento e um significativo processo de exumação pode ter ocorrido logo após a intrusão do magma alcalino (83Ma) e durado aproximadamente 11 milhões de anos, terminando em 72Ma.

O magmatismo alcalino durou do final do Cretaceo até o Paleogeno, formando o grande alinhamento magmático Poços de Caldas-Cabo Frio. Das 22 intrusões que formam o alinhamento, Poços de Caldas é a maior e a mais antiga ( $\sim 83 \mathrm{Ma})$ e as idades vão diminuindo sistematicamente de Oeste pra Leste até a intrusão de Cabo Frio om $\sim 54 \mathrm{Ma}$ (THOMPSON et al. 1998). Esse evento também é verificado de forma muito similar em regiões do continente africano (MOORE et al.., 2008).

As idades de traços de fissão em apatitas da intrusão alcalina abrangem desde o Paleoceno até o Eoceno, e são similares com as obtidas por outros trabalho (SILVA et al. 2011; COGNÉ et al., 2011). Essas idades mais novas que a intrusão estão relacionadas à reativação das antigas zonas de cisalhamento durante o Paleogeno, que foi responsável pelo início da formação do Sistemas de Rift Continentais do Sudeste (ZALÁN \& OLIVEIRA, 2005). Dados de Paleotemperatura obtidos por Hackspacher et. al (2007) mostra que nesse período a região de Poços de Caldas as temperaturas eram acima dos $100^{\circ} \mathrm{C}$, estando bastante acima dos valores regionais até os 65Ma. Os autores interpretam esse máximo como consequência do soerguimento térmico associado ao calor da intrusão alcalina.

As amostras do MAPC também são similares as obtidas por Cogné et al., (2011) apresentando um resfriamento rápido em $\sim 80 \mathrm{Ma}$ até $\sim 40^{\circ} \mathrm{C}$ permanecendo relativamente estável em baixas temperaturas até o Plioceno, quando há um novo resfriamento ráido, o que implica que houve uma rápida exumação dos corpos intrusivos logo após sua formaçao.

Assim é possível afirmar que nas regiões mais elevadas que correspondem ao Maciço Alcalino de Poços de Caldas não há indícios da antiga superfície de aplainamento Gondwana, como afirmava King (1956). Os perfis bauxíticos mapeados indicam a presença de uma superfície nessa região (LEONARDI, et al. 2010), e ainda o retrabalhamento da mesma em certa regiões do Maciço. Entretanto essa superfície não pode ser mais antiga que o Eoceno. Mais estudos e datações são necessárias para confirmar definitivamente essa hipótese.

\section{Conclusão}

Muitos estudos vêm demostrando que o sudeste brasileiro vem sendo palco de eventos que não são típicos de uma margem passiva fazendo com que o relevo tenha uma evolução mais complexa em comparação à outras regiões de margem passiva como Austrália e Î́ndia. No caso do sudeste do Brasil, não é possível considerar em sua evolução apenas um modelo epirogenético e climático.

Como afirma Cogné et al. (2011), a litologia no sudeste do Brasil não é a responsável pelas taxas de resfriamento obtidas em seus dados, que mostram ainda histórias térmicas semelhantes para amostras de composição diferente e ainda histórias térmicas diferentes para rochas de mesma litologia. Essa observação já havia sido feita por outros autores como Tello Sáenz et al. (2005), Franco et al., (2005) e Hackspacher (2007). Assim, o conjunto de dados obtidos para a região do Maciço Alcalino de Poços de Caldas mostra uma evolução da paisagem bastante complexa em que se deve levar em conta tanto os fatores exógenos como endógenos.

O método de datação por Traços de Fissão em Apatitas, mostram que há predomínio de idades mais antigas nas regiões mais baixas e idades mais novas nos topos. Os dados obtidos são confirmados pela modelagem termocinemática que apresentou a partir de simulação matemática complexa idades muito semelhantes as obtidas na realidade. Essa modelagem permitiu verificar quais seriam as idades obtidas utilizando-se outros termocronômetros de mais baixa temperatura.

Assim podemos concluir que a configuração do relevo atual é produto de uma construção policíclica e complexa que se dá através do tempo em uma sucessão 
de eventos que se superpõem uns aos outros. Esta superposição não se dá de maneira aleatória e independente, cada evento é condicionado por eventos pretéritos, ao mesmo tempo em que se torna condicionante de eventos futuros. Além disso, processos correntes não atuam apenas de maneira passiva àqueles que os precederam, agem também de maneira independente de modo a exumá-los, reativa-los, preservá-los ou a extinguir seu registro.

\section{Referencias Bibliográficas}

AB'SABER, A.N., Summit surfaces in Brazil. Revista Brasileira de Geociências 30, 515-516. 2000.

ALMEIDA, F. F. M., Fundamentos Geológicos do Relevo Paulista. Boletim Instituto de Geografia e Geologia-IGGUSP- São Paulo, 41:169-263. 1964

ALMEIDA, F. F. M. Origem e Evolução da Plataforma Brasileira. Rio de Janeiro, DNPM/ DGM. 36p. (Boletim 241) 1967.

ALMEIDA, F. F. M. O alinhamento magmático de Cabo Frio. Simpósio de Geologia do Sudeste 2, Atas SBG, Rio de Janeiro 2, 423-428, 1991.

ALMEIDA, F. F. M., CARNEIRO C.D.R, MISUZAKI A.M.P. Correlação do magmatismo das bacias da margem continental brasileira com o das áreas emersas adjacentes. Revista Brasileira de Geociências 26:125-138, 1996.

ALMEIDA, F. F. M., CARNEIRO C.D.R. Origem e Evolução da Serra do Mar, Revista Brasileira de Geociências 28(2), 135-150, 1998.

ALMEIDA, F. F. M., et al.. The origin and evolution of the South American Platform. Earth-Science Review. 50, 77-111 2000.

AMARAL G, BUSHEE J, CORDANI UG, KAWASHITA K, REYNOLDS JH Potassium-argon ages of alkaline rocks from southern Brazil. Geochim Cosmochim Acta 31:117-142, 1967.

ARAUJO, R.L.C., Pesquisa geotermal na chaminé alcalina de Poços de Caldas. 31st Cong. Bras. Geol., Camboriú, Anais, 2 : 1059-1074, 1980.

BRAUN, J. Quantifying the Effect of Recent Relief Changes on Age-Elevation Relationships. Earth and Planetary Sciences Letters 200:331-343, 2002a.

BRAUN, J. Estimating Exhumation Rate and Relief Evolution by Spectral Analysis of Age-Elevation Datasets. Terra Nova 14: 210-214, 2002b.

BRAUN, J. Pecube: A New Finite Element Code to Solve the
Heat Transport Equation in Three Dimensions in The Earth's Crust Including The Effects of a Time-Varying, Finite Amplitude Surface Topography. Computers and Geosciences 29: 787-794, 2003.

BRAUN, J. Quantitative Constraints on Rate of Landform Evolution Derived from Low-Temperature Thermochronology. Reviews in Mineralogy \& Geochemistry 58: 351-374, 2005.

BUSHEE J. Potassium-argon ages of some alkaline rocks from southern Brazil, p. 145, Ph.D. thesis, University of California at Berkeley, California, 1971.

CAMPOS NETO, M.C. da. Orogenesi systems from southerwestern gondwana na approach to Brasiliano-Pan African cycle and orogenci collage um southeastern Brazil. In: CORDANI, U. G et al.., (edited) Tectonic Evolution of South America. 1a. ed. Rio de Janeiro: 31st International Geological Congress, cap. 12, p.335-365, 1999.

CAVALCANTE, et al.. Projeto Sapucaí. Relatório Final de Geologia - Ministério das Minas e Energia. Departamento Nacional da Produção Mineral. Brasília, 1979.

COBBOLD, P.R., MEISLING, K.E., MOUNT, V.S., Reactivation of an obliquely rifted margin, Campos and Santos basins, southeastern Brazil. AAPF Bulletin. 85, 1925-1944, 2001.

COGNÉ, N., GAllaGHer, K., COBBOLD, P.R., Post-rift reactivation of the onshore margin of southeast Brazil: Evidence from apatite (U-Th)/He and fission-track data. Earth and Planetary Science Letters 309, 118-130, 2011.

DIAS-BRITO, D.; MUSACCHIO, E. A.; CASTRO, J. C. de; MARANHÃO, M. S. A. S.; SUAREZ, J. M.; RODRIGUES, R. Grupo Bauru: uma unidade continental do Cretáceo no Brasil - concepções baseadas em dados micropaleontoló- gicos, isotópicos e estratigráficos. Revue de Paléobiologie. v. 20, n. 1, p. 245-304, 2001.

DONELICK, R. A., Apatite Fission-Track Analysis. Revista Mineralogy and Geochemistry 58, 49-94, 2005.

DORANTI, C.; HACKSPACHER, P.C.; HADLER NETO, J.C.; RIBEIRO, M.C.S.; LIMA, H.C. Evolução do Relevo da Região do Planalto de Poços de Caldas: Correlações Entre Níveis Planálticos e Termocronologia por Traços de Fissão. Geografias, 4(1): 87-92, 2008.

DUNKL, I., Tracckey: a windows program for calculation and graphical presentation of fission track data. Computer and Geosciences. 28, 3-12, 2002.

DUTRA, C. V. Método chumbo-alfa e idades de zircões do maciço alcalino de Poços de Caldas, Minas Gerais. Boletim do 
Instituto de Geologia. EFMOP, v.1, n. 3-4, 1966. Fairbridge (1968).

FRANCO, A. O. B., História Térmica e Denudação do Maciço Alcalino de Poços de Caldas (SP/MG) e Adjacências: Área Sul. Trabalho de Formatura - IGCE-UNESP, Rio Claro, 2003.

FRANCO, A. O. B., HACKSPACHER, P.C.; GODOY, D.F de; HADLER NETO, J.C.., História Térmica do Maciço Alcalino de Poços de Caldas (SP/MG) e Adjacências Através da Análise de Datação por Traços de Fissão em Apatitas. Revista Brasileira de Geociências 35(3): 351-358, 2005.

FRANCO-MAGALHÃES A.O.B., HACKSPACHER, P.C., GLASMACHER, U.A., SAAD, A.R., Rift to post-rift evolution of a "passive" continental margin: the Ponta Grossa Arch, SE Brazil. International Journal of Earth Sciences 99, 1599$1613,2010$.

GALLAGHER, K., HAWKESWORTH, C.J. E MANTOVANI, M.S.M. Denudation, Fission Track Analysis and Long Term Evolution of Passive Margin Topography Application to the Southeast Brazilian Margin. Journal of South American Earth Sciences, V.8. N.1, P.65 - 77, 1994.

GODOY, D. F. DE. 2003. Historia Térmica e Denudação do Maciço Alcalino de Poços de Caldas e Circunvizinhanças: Área Norte. Trabalho De Graduação - Igce-Unesp, Rio Claro-Sp.

HACKSPACHER, P. C; RIBEIRO, L.F.B.; RIBEIRO, M.C.S.; FETTER,A.H.; HADLER NETO,J.C.; S. TELLO, C.E.; DANTAS, E.L. Consolidation and Break-Up of The South American Platform in Southeastern Brazil: Tectonothermal and Denudation Histories. Gondwana Research $-\mathrm{N}^{\mathrm{o}} 1$, P. 91 $-101,2004$.

HACKSPACHER, P. C.; GODOY, D. F.; RIBEIRO, L. F. B.; HADLER NETO, J. C.; FRANCO, A.O.B., Modelagem térmica e geomorfologia da borda sul do Cráton do São Francisco : termocronologia por traços de fissão em apatita. Revista Brasileira de Geociências 37, 76-86, 2007.

HACKSPACHER, P. C.; FETTER, A. H.; EBERT, H. D.; VALDECER, A.; JANASI, V. A.; DANTAS, E. L.; OLIVEIRA, M. A. F.; BRAGA, I. Magamatismo Cálcio-alcalino a ca 660640 Ma no Domínio Socorro: Registros de Convergência précolisional na aglutinação do Godwana Ocidental. Revista IG (Universidade de São Paulo), Série Cientifica, 85-96, 2003.

HAMZA, V.M., CARDOSO, R.A. E GOMES, A.J.L, Gradiente e Fluxo Geotérmico na Região Sudeste: Indícios de Calor Residual do Magmatismo Alcalino e Implicações para Maturação Térmica de Sedimentos na Plataforma Continental. III Simpósio de Vulcanismo e Ambientes Associados Cabo Frio, Rj - 2005.
HEILBRON, M.; PEDROSA-SOARES, A.C.; CAMPOS NETO, M. C.; SILVA, L.C.; TROUW, R.A.J.; JANASI, V.A.; - Província Mantiqueira, P. 204-234. In: MANTESSO-NETO, V.; BARTORELLI, A.; CARNEIRO, C.D.R.; BRITO-NEVES, B.B.; (ORG) Geologia do Continente Sul-Americano: Evolução da Obra de Fernando Flávio Marques de Almeida, São Paulo, Beca, 647p., 2004.

HIRUMA, S.T., RICCOMINI, C., MODENESI-GAUTTIERI, M.C., HACKSPACHER, P.C., NETO, J.C.H., FRANCOMAGALHÃES, A.O.B., Denudation history of the Bocaina Plateau, Serra do Mar, southeastern Brazil: Relationships to Gondwana breakup and passive margin development. Gondwana Research 18, 674-687, 2010.

HOUSE, M. A., WERNICKE, B. P., AND FARLEY, K. A., Dating Topography of the Sierra Nevada, California, Using Apatite (U-Th)/He Ages: Nature, V. 396, p. 66-69, 1998.

KARL, M., GLASMACHER, U. A., KOLLENZ, S., FRANCOMAGALHAES, A.O.B., STOCKLI, D.F., HACKSPACHER, P.C., Evolution of the South Atlantic passive continental margin in southern Brazil derived from zircon and apatite (U-Th-Sm)/ He and fission-track data. Tectonophysics 604, 224-244, 2013.

KAWASHITA, K., MAHIQUES, M.M. AND ULBRICH, H.H.G.J., Idades $\mathrm{Rb} / \mathrm{Sr}$ de nefelina sienitos do Anel Norte do Maciço Alcalino de Poços de Caldas, MG-SP. In: 33rd Congresso Brasileiro Geologia, Rio de Janeiro, Resumos, pp. 244-245. 1984.

KETCHAM, R.A., Forward and inverse modeling of lowtemperature thermo- chronometry data. Reviews in Mineralogy and Geochemistry 58, 275-314, 2005.

KING, L.C. - A Geomorfologia do Brasil Oriental. Revista Brasileira de Geografia, V.18, N.2, P.147-265. 1956

LEONARDI, F.A., SÉRGIO, F., LADEIRA, B., N.D. Perfis Bauxíticos do Planalto de Poços de Caldas SP/MG - Análise Geoquímica e Posição na Paisagem. Revista de Geografia. Recife: UFPE - DCG/NAPA, v. especial VIII SINAGEO, n. 1, Set. 201045

MAGALHÃES JR., A. P.; TRINDADE, E. de S., 2004. Relações entre Níveis ( Paleo ) Topográficos e Domínios Morfotectônicos na Região Sul de Minas Gerais: Contribuições aos Estudos de Superfícies Erosivas no Sudeste Brasileiro. Revista Brasileira Geomorfologia. 1, 1-10, 2004.

MANTESSO NETO; A. BARTORELLI; C.D.R. CARNEIRO; B.B.B. NEVES (EDS.). Geologia do Continente SulAmericano: Evolução da Obra de Fernando Flávio Marques de Almeida. Sociedade Brasileira de Geologia, São Paulo: 
Beca, p. 595-612, 2004.

MILANI, E.J. Comentários sobre a origem e a evolução tectônica da Bacia do Paraná. In: MANTESSO-NETO, V.; BARTORELLI, A.; CARNEIRO, C.D.R.; BRITO-NEVES, B.B. (Org.). Geologia do Continente Sul Americano: evolução da obra de Fernando Flávio Marques de Almeida. São Paulo: Beca. p. 265-280, 2004.

MOORE, A., BLENKINSOP, T., COTTERILL, F. (Woody), 2008. Controls on post-Gondwana alkaline volcanism in Southern Africa. Earth Planetary Science Letters 268, 2008.

MOREIRA, É.C., AlBERTO, L., FERNANDES, D.Á., PEREIRA, V.P. A Análise de Lineamentos Estruturais, Sob a Óptica da Geometria Fractal, no Maciço Alcalino de Poços de Caldas ( MG ). Revista Pesquisas em Geociências 34, 89-97, 2007.

POCAY, M.A.H. Análise termocronologica da Serra do Gavião e do Morro do Cristo, Poços de Caldas MG. Relatório de Qualificação de Mestrado. IGCE, UNESP, Rio Claro, 60p. 2012;

PONÇANO, W. L., CARNEIRO, C. D. R., BISTRICHI, C. A., AlMEIDA, F. F. M. E PRANDINI, F. L. - Mapa Geomorfológico do Estado de São Paulo. São Paulo, Ipt (Ipt, Monografias, 5). Escala: 1:1 000 000, 1981.

RABASSA, J., CARIGNANO, C., CIOCCALE, M., 2010. Gondwana paleosurfaces in Argentina : an introduction. Geociências 29, 439-466.

REINERS, P.W., SHUSTER, D.L., Thermochronology and Landscape evolution. Physics Today 31-36, 2009.

RICCOMINI C; SANT'ANNA, L.G; FERRARI A.L; Evolução Geológica do Rift Continental do Sudeste do Brasil. In: MANTESSSO-NETO V; BARTORELLI A.; CARNEIRO, C.D.R; BRITO NEVES, B.B. de; Geologia do Continente Sul Americano: Evolução da Obra de Fernando Flávio Marques de Almeida. Beca, São Paulo 383-405p. 2004.

SAADI, A., SILVA, L.M. \& MAGALHÃES Jr., A.P, Contribuição à Discussão das Superfícies de Aplainamento no Sudeste Brasileiro, com Base na Análise Quantitativa da Paleotopografia do Sul de Minas Gerais. Geosul. Florianópolis: Departamento de Geociências CFH, 14(27) 569-572 (Edição Especial, Simpósio Nacional de Geomorfologia, 2), 1998.

SADOWSKI, G.R., DIAS NETTO, C. de M. O Lineamento Tectônico de Cabo Frio. Revista Brasileira de Geociências. 11 (4), 209-212, 1981.

SCHOBBENHAUS, C.; CAMPOS,D.A; DERZE,G.R.; HASMUS,H.E. (Coordenadores). -. Mapa Geológico do Brasil e da Área Oceânica Adjacente Incluindo Depósitos Minerais, Escala 1: 2500 000- Brasília DNPM, 4 Folhas, 400p., 1981.

SILVA, J.S., GLASMACHER, U.A., HACKSPACHER, P. C.; STOCKLI, D.; KARL, M.; SEHRT, M., The Poços de Caldas alkaline massif, a key to understand thermal, exhumation, rock and surface uplift history at the " passive" continental margin of Brazil, in: EGU General Assembly. Vienna, p. 2011, 2011.

SILVA. J. S. Reconstrução termocronologica do maciço alcalino de Poços de Caldas e áreas adjacentes por traços de fissão e (U-Th-Sm) \he em apatitas e zircão. Trabalho de Conclusão de Curso, Bacharel em Geografia, UNESP. Rio Claro, 2010.

SLAVEC, G. DE B., MANTOVANI, M. S. M. \& SHUKOWSKY, W. Estudo Gravimétrico do Maciço Alcalino de Poços de Caldas. Revista Brasileira de Geociências 34(2):275-280, 2004.

SOUZA, D.H. de Modelagem evolutiva da paisagem do planalto sul de Minas através de correlações entre análise morfométrica da rede de drenagem e termocronologia por traços de fissão em apatitas. (Dissertação Mestrado em Geologia Regional), IGCE, UNESP, Rio Claro-SP; 150f, 2013.

TANKARD, A.J., ULIANA, M.A., WELSINK, H.J., RAMOS, V.A., TURIC, M., FRANÇA, A.B., MILANI, E.J., BRITO NEVES, B.B., EYLES, N., SKARMETA, J., SANTA ANA, H., WIENS, F., CIRBIÁN, M., PAULSEN, O.L., GERMS, G.J.B., DE WIT, M.J., MACHACHA, T., MILLER, R.MCG., Tectonic controls of basin evolution in southwestern Gondwana. In: Tankard, A.J., Suarez, R., Welsink, H.J. (Eds.), Petroleum Basins of South America, AAPG Memoir 62, pp. 5-52, 1995.

TELLO SAENZ, C.., HACKSPACHER, P.., HADLER NETO, J.., IUNES, P.., GUEDES, S., RIBEIRO, L.F.., PAULO, S.., Recognition of Cretaceous, Paleocene, and Neogene tectonic reactivation through apatite fission-track analysis in Precambrian areas of southeast Brazil: association with the opening of the south Atlantic Ocean. Journal of South American Earth Sciences 15, 765-774, 2003.

TELlO SAENZ, C. A., HADLER NETO, J.C., IUNES, P.J., GUEDES, S., HACKSPACHER, P.C., RIBEIRO, L.F.B., PAULO, S.R., OSORIO A, A. M., Thermochronology of the South American platform in the state of São Paulo, Brazil, through apatite fission tracks. Radiaion Measurements 39, 635-640, 2005.

THOMAZ FILHO, A.; RODRIGUES, A. L. O alinhamento de rochas alcalinas Poços de Caldas-Cabo frio (RJ) e sua continuidade na cadeia Vitória-Trindade. Revista Brasileira de Geociências, Rio de Janeiro, v. 2, n. 29, p. 189-194, jun. 1999. 
THOMAZ FILHO, A., CESERO, P. DE, MIZUSAKI, A.M., LEÃO, J.G., Hot spot volcanic tracks and their implications for South American plate motion, Campos basin (Rio de Janeiro state), Brazil. Journal of South American Earth Sciences 18, 383-389, 2005.

THOMPSON, R.N., GIBSON, S.A., MITCHELL, J.G., DICKIN, A.P., LEONARDOS, O.H., BROD, J.A., GREENWOOD, J.C., Migrating Cretaceous-Eocene magmatism in the Serra do Mar Alkaline provinces, SE Brazil: melts from the deflected Trindade Mantle Plume?. Journa of Petrology 39 (8), 1493-1526, 1998.

TORQUATO,J.R. \& CORDANI, U. G. Brazil- Africa geological links. Earth-Science Reviews, 17, 155-176, 1998.

VISSER, J.N.J. The palaeogeography of part of southwestern Gondwana during the Permian-Carboniferous glaciation. Palaeogeography Palaeo-Climatology, Palaeoecology, 61, 205-219, 1987.
Ulbrich, H.H.G.J.; VLACH., S.R.F.; Ulbrich M.N.C. AND Kawashita, K.,Penecontemporaneous Syeniticphonolitic dnd Basic-Ultrabasic-Carbonatitic Rocks at the Poços de Caldas Alkaline Massif, SE Brazil: Geological and Geochronological Evidence. Revista Brasileira de Geociências, 32: 15-26, 2002.

ZALÁN, P. V. Evolução fanerozóica das bacias sedimentares brasileiras. In: V. MANTESSO NETO; A. BARTORELLI; C.D.R. CARNEIRO; B.B.B. NEVES (EDS.). Geologia do Continente Sul-Americano: Evolução da Obra de Fernando Flávio Marques de Almeida. Sociedade Brasileira de Geologia, São Paulo: Beca, p. 595-612, 2004.

ZALAN, P. V., \& OLIVEIRA, J. B. A. Origem e Evolução Estrutural do Sistema de Riftes Cenozóicos do Sudeste do Brasil; Boletim de Geociências da Petrobras, Rio De Janeiro, V. 13, N. 2, P. 269-300. 2005. 